\title{
Determination of thermodynamic complexity constants and speciation for multi-complexing electrolytes within the mean spherical approximation model
}

\author{
Jean-Pierre Simonin* \\ CNRS, Laboratoire PHENIX, Campus P.M. Curie, Sorbonne Universités, F-75005, Paris, \\ France. \\ E-mail: jpsimonin@gmail.com
}

\begin{abstract}
It has been shown in previous work that the determination of speciation in aqueous solutions containing self-complexing electrolytes requires caution as regards the thermodynamic model used to estimate the activity coefficients of the solute species, and the complexity constants values, which seem uncertain if not irrelevant in some cases. This topic was studied using a simple molecular model based on the mean spherical approximation (MSA) theory. In the present work, the case of aqueous ternary mixtures with common chloride anion is considered within the same framework. The mixtures are composed of a self-complexing 2-1 salt, $\mathrm{MCl}_{2}$, and of a strong 1-1 or 2-1 salt containing chloride at $25^{\circ} \mathrm{C}$. The metal cation $\mathrm{M}^{2+}$ is $\mathrm{Mn}^{2+}, \mathrm{Co}^{2+}, \mathrm{Ni}^{2+}, \mathrm{Cu}^{2+}, \mathrm{Zn}^{2+}$, $\mathrm{Cd}^{2+}$ or $\mathrm{Pb}^{2+}$. Complexity constants values for the divalent cations were obtained by optimizing the representation of experimental osmotic or activity coefficients for binary and ternary electrolyte solutions, and at the same time by imposing constraints on the
\end{abstract}


speciation, when such experimental data are available. Solutions of $\mathrm{ZnCl}_{2}$ were found to exhibit a peculiar behavior.

\section{Introduction}

The subject of speciation in ionic solutions in which complexation occurs is important in various domains such as environment, toxicology (human and ecological), and sometimes in the industry. Typical multi-associating ions are multivalent metal cations, such as divalent cations $\mathrm{Zn}(\mathrm{II}), \mathrm{Cd}(\mathrm{II})$ or $\mathrm{Pb}(\mathrm{II})$, trivalent cations $\mathrm{Eu}(\mathrm{III}), \mathrm{Am}(\mathrm{III})$ or $\mathrm{Cm}(\mathrm{III})$, or tetravalent cations $\mathrm{Th}(\mathrm{IV})$ or $\mathrm{Pu}(\mathrm{IV})$. These tri- and tetravalent ions, which are mainly encountered in the nuclear industry, are very harmful to living beings. Divalent metal cations are often met in environmental pollution measurements. ${ }^{1}$ For example, $\mathrm{Pb}(\mathrm{II})$ is a major toxic trace metal in natural waters. These cations may associate with anions such as halides, e.g., $\mathrm{Cl}^{-}$ or $\mathrm{Br}^{-}$, and form various complexes $\mathrm{MCl}_{n}^{2-n}$ in which $n$ is the stoichiometry of the complex and $2-n$ is its charge.

In environmental and toxicological studies, a key parameter is the concentration of free metal cation because, generally, this is the most toxic form of a metal in solution. ${ }^{1-3}$ The composition of the medium in which the cation is present determines its degree of complexation and, consequently, the amount of free metal in this medium. For example, free zinc(II) or cadmium(II) ions may be present in their free form in the pure water of a river but, when they arrive at the mouth of the river, they meet seawater chloride anions in substantial concentration (of $\sim 0.6 \mathrm{M}$ ), with which they may form complexes. Consequently the toxicity of the cation may be greatly lowered when it arrives into the sea (if however one neglects the metal cation which may be adsorbed on colloids and rock pieces in suspension and might be released from these substrates when they meet salty water).

Various programs are available for the estimation of speciation in aqueous solutions. They can be useful to researchers working in toxicological, environmental and chemical engineer- 
ing areas, who wish to assess the amounts of the various forms of a chemical species in a particular medium (e.g., a pollutant like $\mathrm{Zn}^{2+}, \mathrm{Cd}^{2+}$ or $\mathrm{Hg}^{2+}$ in natural waters). The speciation may be computed for very complicated mixtures, composed of many metal cations and complexing anions. Examples of these programs are MINEQL+, CHESS, SPECIES, MINTEQ, PHREEQC and CHEAQS, ${ }^{4-9}$ the last four being free of charge. The determination of speciation is based on the numerical solution of the various, sometimes coupled, chemical association equilibria. Values for the thermodynamic association constants are generally taken from the literature. The computations involve formulas for the estimation of the activity coefficients of the species. Deviations from ideality arising from electrostatic interactions are computed using equations of the Debye-Hückel type with a correction, such as the Davies equation ${ }^{10}$ in CHESS, MINTEQ, PHREEQC, or the specific interaction theory ${ }^{11}$ (SIT) which is also available in MINTEQ for more concentrated solutions.

This paper is the continuation of previous work ${ }^{12}$ (hereafter referred as I) which was dedicated to the case of binary aqueous solutions of self-complexing electrolytes. In this work, it was found that the use of the Davies equation did not yield good results for the mean salt activity coefficient, $\gamma_{S}$, in such solutions. First the Davies equation was found to be inaccurate in the case of strong electrolytes above $0.1 \mathrm{M}$, this inaccuracy increasing dramatically with salt concentration (see Figure 1 of ref. I). Next, a thermodynamic inconsistency was observed in the case of some self-complexing electrolytes (e.g., $\mathrm{ZnCl}_{2}, \mathrm{CdBr}_{2}$ ), in the sense that $\gamma_{S}$ exhibited a significant deviation from experimental data when literature values for the complexity constants were used in the computations. A description in terms of the mean spherical approximation (MSA) theory was proposed to replace the Davies equation.

The MSA is not an empirical model. It was derived from a statistical mechanical treatment of ions in a dielectric continuum. ${ }^{13,14}$ It can consistently describe osmotic and activity coefficients for electrolytes up to very high concentrations (to saturation in general) when concentration-dependent solution permittivity and cation size are introduced. ${ }^{15-17}$ In ref. I, a simplified MSA model was proposed to represent activity coefficients up to ionic strengths 
of about $3 \mathrm{M}\left(I=\frac{1}{2} \sum_{k} z_{k}^{2} C_{k}\right)$, which corresponds to concentrations of $3 \mathrm{M}$ for a strong 1-1 charge type salt, or of $1 \mathrm{M}$ for a strong 2-1 salt (ionic strength is a notion adapted to mixtures of salts of different stoichiometries). The use of this model in the speciation problem showed that some complexity constants seemed to be incorrect, as in the case of $\mathrm{ZnCl}_{2}, \mathrm{ZnBr}_{2}$, $\mathrm{CdBr}_{2}$ and $\mathrm{CdI}_{2}$, because they led to large deviations in the mean salt activity coefficient. Thermodynamically consistent complexity constants were obtained by minimizing the deviation of activity coefficients, computed by employing the MSA model, from the experimental ones. However these were provisional values that had to be confirmed by a closer analysis. One of the main reasons is that these salts are generally assumed to form 4 types of complexes. Consequently one may expect many sets of complexity constants to give satisfactory representations of $\gamma_{S}$. Nonetheless it was suggested that the case of mixtures with common anion could facilitate the determination of more constrained complexity constants because this type of system is expected to produce a higher degree of association and larger amounts of complexes of higher stoichiometry.

In the present study the case of mixtures is addressed within the MSA, as was done in ref. I. However, in contrast with ref. I, since mostly osmotic coefficient data $(\phi)$ are available in the literature for these mixtures, it was thought preferable to handle thermodynamicallyconsistent osmotic and ionic activity coefficients (this was not the case in ref. I, in which only mean salt activity coefficients were optimized). This constraint requires the use of the so-called McMillan-Mayer-to-Lewis-Randall (MM-to-LR) conversion of these quantities. The LR level is that of the experiment (the 'real world') while the MM level is that of the theoretical model (at which the solution is in osmotic equilibrium with pure water ${ }^{18}$ ). As explained below, the conversion formula utilized here is rather simple and only requires a knowledge (parametrization) of solution densities. Besides this modification, the type of model employed here is similar to that of ref. I.

The ternary mixtures considered in this work contain the metal cation $\mathrm{Mn}^{2+}, \mathrm{Co}^{2+}$, $\mathrm{Ni}^{2+}, \mathrm{Cu}^{2+}, \mathrm{Zn}^{2+}, \mathrm{Cd}^{2+}$, or $\mathrm{Pb}^{2+}$, the chloride anion, $\mathrm{Cl}^{-}$, and another cation that does 
not associate with chloride. All of these cations are usual contaminants of natural waters. ${ }^{1}$ Their chloride complexes are clearly of upmost importance in geochemical studies involving seawater, brines and hydrothermal solutions ${ }^{1,19,20}$ in which the chloride ion is the major anion (ca. $0.6 \mathrm{M}$ in seawater and up to several molar in natural brines). Zinc chloride is moreover a particularly interesting salt because of the wide range of complexity constants values that have been reported in the abundant literature about this salt, ${ }^{21}$ and because of its peculiar, both thermodynamic and transport, properties that have been long pointed out in the literature. ${ }^{22,23}$

This paper is organized as follows. The next section summarizes the experimental information available about the salt solutions studied in this work. The thermodynamic data include experimental measurements for binary and ternary solutions. Then the method used to determine the speciation in these solutions is exposed in the third section. This section includes a description of the thermodynamic MSA model. The fourth section is devoted to the presentation and discussion of the results. The last section gives some concluding remarks.

\section{Experimental information available}

\section{Complexity constants}

Hereafter we will mainly be concerned with ternary aqueous mixtures of an auto-associating salt, denoted by $\mathrm{MCl}_{2}$, with a strong salt, denoted by $\mathrm{NCl}_{p}$ (with $p=1$ or 2 ). The former salt is composed of the divalent metal cation $\mathrm{M}^{2+}$ and the halide anion $\mathrm{Cl}^{-}$, which gives rise to self-complexation according to the following equilibria,

$$
\mathrm{M}^{2+}+n \mathrm{Cl}^{-} \leftrightarrows \mathrm{MCl}_{n}^{2-n} \quad\left(\beta_{n}\right)
$$


in which $\beta_{n}$ is the cumulative complex formation constant (on molarity scale) corresponding to the association of the metal cation with $n$ anions,

$$
\beta_{n}=\frac{y_{n}}{y_{0}\left(y_{C l^{-}}\right)^{n}} \frac{C_{n}}{C_{0}\left(C_{C l^{-}}\right)^{n}}
$$

where $y$ and $C$ denote activity coefficient and concentration, respectively, on molarity scale. Subscript $n$ denotes the number of anions in the complex $\mathrm{MCl}_{n}^{2-n}$. The subscript $n=0$ is used to designate the free metal ion $\mathrm{M}^{2+}$. So, $C_{0} \equiv C\left(\mathrm{M}^{2+}\right)$ and $C_{n} \equiv C\left(\mathrm{MCl}_{n}^{2-n}\right)$. For most metal cations considered in this work, experiment has suggested a maximum value of $n=4$. Let us note that polynuclear complexes may appear, but mainly in highly concentrated solutions, ${ }^{21,22}$ e.g., in solutions of $\mathrm{CuCl}_{2}$ or $\mathrm{ZnCl}_{2}$ (above $10 \mathrm{M}^{22}$ ), which will not be the case here.

It should be mentioned that the value of $\beta_{n}$ on molality scale may be deduced ${ }^{24}$ from that on molarity scale by dividing the latter by $d_{0}{ }^{n}$ (with $d_{0}=0.997045 \mathrm{~kg} \mathrm{~L}^{-1}$ the density of pure water at $25^{\circ} \mathrm{C}$ ). The two are therefore numerically very close for any value of $n \leq 4$.

Values for the $\beta_{n}$ 's of many cations have long been reported in the literature. Many of these values have been collected in famous compilations, which include the critical tables of Sillen and Martell ${ }^{21}$ and Smith and Martell, ${ }^{25}$ and the IUPAC and NIST databases. ${ }^{6,26}$ More recently, a series of critical IUPAC technical reports has been published which gives an updated account of the complexity constants of $\mathrm{Hg}$ (II), $\mathrm{Cu}$ (II), $\mathrm{Pb}(\mathrm{II}), \mathrm{Cd}(\mathrm{II})$ and $\mathrm{Zn}$ (II) ${ }^{27-31}$ which all occur at trace levels in fresh water and seawater. ${ }^{32}$ In the latter series of publications the SIT model ${ }^{11}$ was employed to describe deviations from ideality. A look at these references shows that a large scatter generally exists in the various sets of published complexity constants. As might be expected, this is particularly so in the case of weak or relatively weak complexes like, e.g., $\mathrm{ZnCl}_{2}$ or $\mathrm{CuCl}_{2}$. 


\section{Structure of the complexes}

In the present work, as well as in ref. I, the structure of the complexes determines the size to be taken for these compounds in the thermodynamic calculations. In the model used here, the solute species are all modeled as (possibly charged) hard spheres. An effective diameter is assigned to these spheres, depending on the number of chloride ions and water molecules bound to the central metal cation. This diameter also depends on the type of complex, viz. covalent or ionic.

The metal cations studied in this work are $\mathrm{Mn}^{2+}, \mathrm{Co}^{2+}, \mathrm{Ni}^{2+}, \mathrm{Cu}^{2+}, \mathrm{Zn}^{2+}, \mathrm{Cd}^{2+}$ and $\mathrm{Pb}^{2+}$. It seems well established that all of these cations have an octahedral structure in their free state, ${ }^{33}$ of formula $\mathrm{MW}_{6}^{2+}$ (with $\mathrm{W}$ standing for the water molecule).

In contrast, the study of complexes has often been the subject of controversy, seemingly because various techniques probe different properties of these species, and because spectra obtained using a given technique are difficult to interpret and may lead to different conclusions. This phenomenon may be observed for instance in the case of $\mathrm{NiCl}_{2}$ which has been studied extensively in the literature. ${ }^{34}$

In the case of zinc, it must be noticed that the monochloride complex, $\mathrm{ZnCl}^{+}$, should be at least partly an outer-sphere ionic complex (solvent-separated ion pair), not a covalent one, according to two studies using different experimental techniques. ${ }^{35,36}$ Apparently this is also the case of the $\mathrm{NiCl}^{+}$complex for which various $\mathrm{X}$-ray studies found no chloride in contact with the nickel ion. ${ }^{34,37-40}$ All other monochloride complexes were assumed to be covalent. The complexes of higher stoichiometry were all supposed to have the same structure. Namely, the dichloro complexes were regarded as being hexa-coordinated, of formula $\mathrm{MCl}_{2} \mathrm{~W}_{4}^{0}$, as was proposed for zinc. ${ }^{35}$ The tri- and tetra-chloro complexes were taken as being tetra-coordinated, with formulas $\mathrm{MCl}_{3} \mathrm{~W}^{-}$and $\mathrm{MCl}_{4}^{2-}$, again similarly to what was hypothesized in the case of zinc. ${ }^{35,41-44}$ The change of coordination number from 6 to 4 has been attributed to the fact that it lowers the electrostatic repulsion between the charges on the chlorides. ${ }^{42}$ 


\section{Speciation and mean coordination number of the metal cation}

Some experimental data about the speciation in binary solutions of $\mathrm{ZnCl}_{2}$ may be found in the literature. These data were obtained by using dielectric spectroscopy. ${ }^{36}$ They included estimations of the proportions of free ions and of the first complex.

X-ray diffraction and EXAFS (Extended X-Ray Absorption Fine Structure spectroscopy) have provided an invaluable direct information by probing the first shell about the cation. Several studies have convincingly concluded to the absence of chloride ions in the first coordination sphere of the nickel ion. ${ }^{34,37-40,45}$ Other works have provided information about the presence, or absence, of $\mathrm{Cl}^{-}$ions in the first shell of most cations considered in this work, including $\mathrm{Mn}(\mathrm{II}),{ }^{46} \mathrm{Co}(\mathrm{II}),{ }^{45,47} \mathrm{Cu}(\mathrm{II}),{ }^{34,45,48} \mathrm{Zn}(\mathrm{II}),{ }^{49}$ and $\mathrm{Cd}(\mathrm{II}) .{ }^{40}$

By denoting by $p_{n}$ the proportion of a complex of stoichiometry $n$ for a complex $\mathrm{MCl}_{n}$, the mean coordination number of the metal cation with chlorides may be defined as,

$$
N_{C l} \equiv \sum_{n=n_{0}}^{4} n p_{n}
$$

with $n_{0}=1$ when the first complex $\mathrm{MCl}^{+}$is covalent, and $n_{0}=2$ when it is of ionic nature (no chlorine present in the first coordination shell).

The available experimental data related to the speciation and to $N_{C l}$ (in the concentration range of this study) are summarized in Table 1. Experimental uncertainties on these measurements were either found in the reference or estimated from the apparent accuracy of the experiment. Note that in Table 1 most measurements refer to concentrations higher than $1 \mathrm{~mol} \mathrm{~kg}^{-1}$ but it was verified that the corresponding ionic strength was lower than $3 \mathrm{M}$ (because of association).

\section{Thermodynamic data}

Thermodynamic data are available in the literature for aqueous solutions of self-complexing salts in the case of binary solutions and ternary mixtures with strong salts in water. In this 
Table 1: Experimental information on the speciation and on $N_{C l}$.

\begin{tabular}{lccc}
\hline Salt & Ref. & Experimental data & Uncertainty \\
\hline $\mathrm{MnCl}_{2}$ & 46 & $N_{C l}=0.4$ at $1 \mathrm{M}$ & $50 \%$ \\
$\mathrm{CuCl}_{2}$ & 48 & $N_{C l}=0.8$ for $0.1 \mathrm{M} \mathrm{CuCl}_{2}+0.8 \mathrm{M} \mathrm{NaCl}$ & $50 \%$ \\
& 48 & $N_{C l}=1$ for $0.1 \mathrm{M} \mathrm{CuCl}_{2}+2.8 \mathrm{M} \mathrm{NaCl}$ & $25 \%$ \\
$\mathrm{ZnCl}_{2}$ & 36 & $p_{0}=0.51$ at $1.62 \mathrm{M}$ & $20 \%$ \\
& 36 & $p_{0}=0.46$ at $2.08 \mathrm{M}$ & $20 \%$ \\
& 36 & $p_{1}=0.14$ at $1.47 \mathrm{M}$ & $20 \%$ \\
& 36 & $p_{1}=0.12$ at $1.89 \mathrm{M}$ & $20 \%$ \\
& 49 & $N_{C l}=0.9$ at $1 \mathrm{~mol} \mathrm{~kg}^{-1}$ & $7 \%$ \\
& 49 & $N_{C l}=1.6$ at $2 \mathrm{~mol} \mathrm{~kg}^{-1}$ & $7 \%$ \\
\hline
\end{tabular}

work, such data for binary and ternary solutions were considered in the calculations.

In the case of mixtures, publications mainly report osmotic coefficient values. Measurements of activity coefficients are scarce. In the present work, such values were found only for $\mathrm{HCl}$ in the mixture $\mathrm{ZnCl}_{2}+\mathrm{HCl}$ and for $\mathrm{CdCl}_{2}$ in $\mathrm{CdCl}_{2}+\mathrm{NaCl}$ solution.

Values for the osmotic and mean salt activity coefficients, $\phi$ and $\gamma_{ \pm}$, for binary solutions were retrieved from the Gamphi program developed by the NBS. ${ }^{50}$

\section{Determination of speciation}

In this section, we expose the ingredients of the method utilized in this study to compute the speciation in ternary (and binary) mixtures.

\section{Solution of complexation equilibria}

The aqueous mixture is composed of the auto-complexing salt $\mathrm{MCl}_{2}$ and of the strong $\mathrm{NCl}$ 1-1 salt, or $\mathrm{NCl}_{2} 2-1$ salt. For convenience we will hereafter denote by A the self-complexing salt $\mathrm{MCl}_{2}$ and by $\mathrm{B}$ the strong salt $\mathrm{NCl}$ or $\mathrm{NCl}_{2}$.

For a given solution composition and a given set of $\beta_{n}$ values for $n$ going from 1 to 4 , the speciation (viz. the set of $C_{n}$ values) was found by employing a Newton-Raphson method in 6 dimensions. The 6 equations to solve were the 4 equations for the equilibria (Eq. 2 for 
$n=1, \ldots, 4)$ in which the activity coefficients, $y_{n}$, were computed according to the MSA model, plus the 2 relations for the conservation of total $\mathrm{M}$ and $\mathrm{Cl}$ (the concentration of $\mathrm{N}^{+}$or $\mathrm{N}^{2+}$ is not modified by association). In the Newton-Raphson algorithm, the equations were written as a function of the variables $\left\{\ln C_{n}\right\}$ (not the $C_{n}$ 's) in order to avoid the appearance of negative values of the $C_{n}$ 's in the iterations. The inverse of the $6 \times 6$ Jacobian matrix was calculated analytically, and thereafter translated directly into FORTRAN, by using Maple (the symbolic calculation software). Equilibration was performed at the McMillan-Mayer level.

In practice the speciation in a solution $\mathrm{S}$ was found as follows. First a dilute mixture $\mathrm{S}_{1}$ was considered that had the same solute mole fractions of $\mathrm{A}$ and $\mathrm{B}$ as in $\mathrm{S}$, and in which the total chloride concentration was $\lesssim 0.1 \mathrm{M}$. For this composition, the system of equations was solved analytically by neglecting deviations from ideality (ideal value $y_{i}=1$ for all species). The same was done for a solution $\mathrm{S}_{2}$ that was twice more concentrated than $\mathrm{S}_{1}$. Then, the speciations in the solutions $\mathrm{S}_{3}, \mathrm{~S}_{4}, \ldots$ that were $3,4, \ldots$ times more concentrated than $\mathrm{S}_{1}$, and were now regarded as non-ideal, were determined iteratively by a Newton-Raphson procedure in which the initial speciation was extrapolated from the speciations found in the preceding two iterations. For these solutions $\mathrm{S}_{3}, \mathrm{~S}_{4}, \ldots$, the activity coefficients of the various species were computed within the MSA. The same procedure was repeated until reaching the solution $\mathrm{S}$ (when $\mathrm{S}_{k}=\mathrm{S}$ for some integer $k$ ). For all solutions, the salt concentrations were computed from density data (see next section and the section about densities).

\section{Calculation of concentrations and partial molar volumes}

The content of this section may be found in the Supplementary Information addendum.

\section{MSA model for the deviations from ideality}

The main features of the MSA model and formulas for the activity coefficients were presented in ref. I in the case of binary solutions. We will hereafter explain how to calculate also the 
osmotic coefficient and how to implement the MM-to-LR conversion in the case of mixtures.

The MSA model is derived from statistical mechanics. ${ }^{14}$ An aqueous electrolyte solution is modeled as charged hard spheres (the ions) placed in a dielectric continuum (the water). The various types of ions may have different diameters. The MSA model has similarities with the Debye-Hückel (DH) theory, but it better accounts for the excluded volume effects between the ions. ${ }^{13,51}$ It is developed at the McMillan-Mayer level of solutions in which the solvent is in osmotic equilibrium with pure water. ${ }^{18}$ An important property of the MM level is that the solvent may be considered as a dielectric continuum in this framework, and the pressure of the non-ideal 'gas' of solutes coincides with the osmotic pressure of solution. ${ }^{18,52,53}$ As in ref. I, the relative permittivity of the medium was taken equal to that of water because the solutions considered here are rather dilute.

In the primitive MSA model, a simple ion is modeled as a hard sphere, whose diameter reflects the hard core interactions between ions. Consequently, the ion diameter will be larger than its crystallographic value if the ion is hydrated, ${ }^{54}$ as is the case for $\mathrm{Li}^{+}$or $\mathrm{Mg}^{2+}$ cations $^{15}$ (see section 'Sizes assigned to the solute species' below).

The expression of the activity coefficient of an ion within this primitive MSA is composed of two terms, ${ }^{14,15,54}$ one arising from volume exclusion and another one from electrostatic interactions between ions. It reads,

$$
\ln y_{i}^{(M M)}=\ln y_{i}^{H S}+\ln y_{i}^{e l}
$$

where the superscripts 'MM', 'HS' and 'el' respectively mean McMillan-Mayer, hard sphere and electrostatic.

One has,

$$
\ln y_{i}^{H S}=-\ln x+\sigma_{i} F_{1}+\sigma_{i}^{2} F_{2}+\sigma_{i}^{3} F_{3}
$$

with $\sigma_{i}$ the diameter of $i, x$ the volume fraction of free space (not occupied by solute parti- 
cles). $F_{1}, F_{2}$ and $F_{3}$ are functions given elsewhere, ${ }^{54}$ and

$$
\ln y_{i}^{e l}=-\lambda\left[\frac{\Gamma z_{i}^{2}}{1+\Gamma \sigma_{i}}+\eta \sigma_{i}\left(\frac{2 z_{i}-\eta \sigma_{i}^{2}}{1+\Gamma \sigma_{i}}+\frac{\eta \sigma_{i}^{2}}{3}\right)\right]
$$

in which $\lambda \equiv \beta e^{2} / 4 \pi \varepsilon \varepsilon_{0}$ is twice the Bjerrum length for ion-pair formation, $\beta \equiv 1 / k_{B} T, k_{B}$ is Boltzmann constant, $e$ is elementary charge, $\varepsilon_{0}$ is the permittivity of a vacuum, $\varepsilon$ is the relative permittivity of solution (the dielectric constant of water, $\varepsilon=78.4$ ), and $\Gamma$ is the MSA screening parameter (the analog of the $\kappa$ screening parameter in Debye-Hückel theory) which satisfies the equation,

$$
\Gamma^{2}=\pi \lambda \sum_{i} \rho_{i}\left[\left(z_{i}-\eta \sigma_{i}^{2}\right) /\left(1+\Gamma \sigma_{i}\right)\right]^{2}
$$

in which $\rho_{i}$ is the number density of species $i\left(\rho_{i}=10^{3} N_{A v} C_{i}\right.$, with $N_{A v}$ standing for Avogadro's number, $C_{i}$ in $\mathrm{mol} \mathrm{L}^{-1}$ and $\rho_{i}$ in $\mathrm{m}^{-3}$ ), and $\eta$ is a quantity that cancels out when the ions are of the same size (its definition is given in refs. ${ }^{15,54}$ ). Eq. 7 has the form $\Gamma=f(\Gamma)$. The value of $\Gamma$ may be easily determined numerically by using a simple iterative procedure, starting with the initial value, $\Gamma_{0}=\kappa / 2$ (the value of $\Gamma$ at infinite dilution).

As shown in ref. I, the mean activity coefficient, $y_{A}^{(M M)}$, of the associated salt $\mathrm{A}$ is given by, ${ }^{12}$

$$
\left(y_{A}^{(M M)}\right)^{3}=y_{M^{2+}}^{(M M)}\left(y_{C l^{-}}^{(M M)}\right)^{2} \frac{C_{M^{2+}}}{C_{M}}\left(\frac{C_{C l^{-}}}{C_{C l}}\right)^{2}
$$

with $C_{M}$ and $C_{C l}$ the total concentrations of $\mathrm{M}\left(C_{M}=C_{A}\right)$ and of chlorine, respectively. The mean activity coefficient of added salt $\mathrm{B}$ is $\left(y_{B}^{(M M)}\right)^{3}=y_{N^{2+}}^{(M M)}\left(y_{C l^{-}}^{(M M)}\right)^{2}$ in the case $\mathrm{B}=\mathrm{NCl}_{2}$, and $\left(y_{B}^{(M M)}\right)^{2}=y_{N^{2+}}^{(M M)} y_{C l^{-}}^{(M M)}$ if $\mathrm{B}=\mathrm{NCl}$. These later two relations for $y_{A}^{(M M)}$ and $y_{B}^{(M M)}$ were derived by using the result that the chemical potentials of $\mathrm{A}$ and $\mathrm{B}$ are equal to the sum of the chemical potentials of the corresponding free ions (see pp. 9724-9725 of ref. I).

Then, the activity coefficient of a salt $\mathrm{S}(=\mathrm{A}$ or $\mathrm{B})$ in a mixture is converted to the 
experimental LR level by using the simple approximate formula, ${ }^{18,55}$

$$
\ln y_{S}=\ln y_{S}^{(M M)}-C_{t} V_{S} \phi^{(M M)} / \nu_{S}
$$

with $V_{S}$ the partial molal volume of salt $\mathrm{S}$ in the mixture $\left(V_{S} \equiv \partial V / \partial m_{S}\right), \nu_{S}$ its stoichiometric number, and $C_{t}$ the total solute concentration on a complete dissociation basis,

$$
C_{t} \equiv 3 C_{A}+\nu_{B} C_{B}
$$

in which $\nu_{B}$ is the total stoichiometric number of salt $\mathrm{B}\left(\nu_{B}=2\right.$ for a $\mathrm{NCl}$ salt and $\nu_{B}=3$ for $\mathrm{NCl}_{2}$ ).

The activity coefficient on molar scale, $y_{S}$, can be converted to the molal scale, $\gamma_{S}$, by using the classic formula, ${ }^{15,24,54}$

$$
\gamma_{S}=y_{S} /\left(V d_{0}\right)
$$

We now turn to the osmotic coefficient, which is first calculated at the MM level. It may be derived from the osmotic pressure which is obtained from the general relation,

$$
P_{o s m}=\sum_{i} \rho_{i} \mu_{i}^{(M M)}-F^{(M M)}
$$

in which $\mu_{i}^{(M M)}$ is the chemical potential of $i$ at MM level and $F^{(M M)}$ is the Helmholtz energy of the gas of solute per unit volume. Eq. 12 may be transformed by expanding $\mu_{i}^{(M M)}$ and $F^{(M M)}$ in their ideal and excess parts, which readily yields,

$$
\beta P_{\text {osm }}=\sum_{i} \rho_{i}+\sum_{i} \rho_{i} \ln y_{i}^{(M M)}-\beta \Delta F^{(M M)}
$$

with $y_{i}$ given by Eqs. 4-6, and $\Delta F^{(M M)}=\Delta F^{H S}+\Delta F^{e l}$ in which $\Delta$ indicates an excess quantity (over ideality). Expressions for the HS and el contributions to $\Delta F^{(M M)}$ may be found elsewhere (Eqs. 3 and 29 of ref. ${ }^{54}$ ). In Eq. 12, index $i$ runs on all species present 
in solution, that is free ions and complexes. The first term on the r.h.s. expresses the first deviation from ideality arising from association. Indeed one has $\sum_{i} \rho_{i}<\rho_{t}$, in which $\rho_{t}$ is the sum of densities on a complete dissociation basis, $\rho_{t} \equiv 3 \rho_{A}+\nu_{B} \rho_{B}$, similarly to Eq. 10, or $\rho_{t}=10^{3} N_{A v} C_{t}$.

Then the MM osmotic coefficient is obtained from the classic relation,

$$
\phi^{(M M)}=\beta P_{o s m} / \rho_{t}
$$

We note in passing that for an ideal solution, $P_{o s m}=k_{B} T \rho_{t}$ (van't Hoff relation), and therefore $\phi^{(M M)}=1$ from Eq. 14, as expected.

The osmotic coefficient at the experimental LR level is obtained by conversion of $\phi^{(M M)}$ as, $, 18,55$

$$
\phi=\phi^{(M M)}\left(1-C_{t} V_{ \pm}\right)
$$

with $V_{ \pm}$the mean solute partial molar volume of solution, which is obtained from the relation, ${ }^{55} V_{ \pm}=\partial V / \partial m_{t}$, in which $m_{t} \equiv 3 m_{A}+\nu_{B} m_{B}$ is the total solute molality and the differentiation is done at constant solute fractions of $\mathrm{A}$ and $\mathrm{B}, x_{A}=3 m_{A} / m_{t}$ and $x_{B}=\nu_{B} m_{B} / m_{t}$. The analytic expression of $V_{ \pm}$can easily be obtained by differentiation of $V$ using Eqs. S2 and S4 (see Supplementary Information) with the use of Maple.

The effect of the MM-to-LR conversion on $y_{S}^{(M M)}$ (with $\mathrm{S}=\mathrm{A}$ or B) in Eq. 9 and on $\phi^{(M M)}$ in Eq. 15 was examined for the various mixtures considered in this work. It was found that both are lowered upon conversion. The maximum drop is of $\sim 10 \%$ for $y_{S}^{(M M)}$ and of $\sim 8 \%$ for $\phi^{(M M)}$ at the highest ionic strengths encountered in this work. The effect of the conversion is therefore not negligible.

Results for the mean salt activity coefficients of A and B (given by Eq. 11), and for the osmotic coefficient (Eq. 15), may be compared with experimental measurements for these quantities because both are obtained at the same LR level. This is done below in section "Results for the $\beta_{n}$ 's". 


\section{Gibbs-Duhem relation}

It was verified that the formulas for the activity and osmotic coefficients in the FORTRAN program satisfy the Gibbs-Duhem relation both at the MM and at the experimental LR level. In the case of ternary solutions it reads,

$$
\mathrm{d}\left[\left(3 m_{A}+\nu_{B} m_{B}\right)(1-\phi)\right]+3 m_{A} \mathrm{~d}\left[\ln \gamma_{A}\right]+\nu_{B} \mathrm{~d}\left[\ln \gamma_{B}\right]=0
$$

at the LR level. A similar relation may be written down at the MM level, by replacing molalities by molar concentrations, $\phi$ by $\phi^{(M M)}$, and the $\gamma_{i}$ 's by the $y_{i}$ 's.

Let us stress that $\gamma_{A}^{(M M)}, \gamma_{B}^{(M M)}$ (with $\gamma_{S}^{(M M)}=y_{S}^{(M M)} /\left(V d_{0}\right)$ by which $y_{S}^{(M M)}$ is converted to molality scale), and $\phi^{(M M)}$ do not satisfy the Gibbs-Duhem relation. MM-to-LR conversion (Eqs. 9 and 15) is required to obtain quantities on molality scale that indeed satisfy this fundamental relation.

Fulfilment of Eq. 16 was examined numerically for various arbitrary values of the $\beta_{n}$ 's. The differentials $(\mathrm{d}[\cdots])$ were computed in the vicinity of 2 particular molalities, e.g. $m_{A}=$

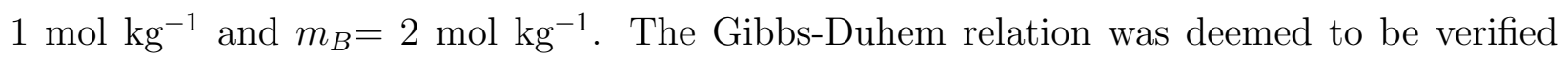
when the sum of the 3 terms in Eq. 16 was much smaller than any of the 3 terms. This was found to be the case for any values of $m_{A}$ and $m_{B}$, with a typical accuracy of the order of $10^{-8}$ or $10^{-9}$ in a double precision FORTRAN program.

The numerical fulfilment of Eq. 16 is a stringent condition that ensures, with a high level of confidence, that all thermodynamic quantities $\left(\phi^{(M M)}, \phi\right.$, the $y_{i}$ 's and the $\gamma_{i}$ 's) are calculated correctly in the program. It was observed that even a slight modification in a single formula of the FORTRAN program resulted in a clear unfulfillment of the GibbsDuhem relation.

\section{Diameters of species for MSA model}

The sizes of the various species for input into the MSA model were taken as follows. 
The diameters of the free cations $\mathrm{M}^{2+}$ (denoted by $\sigma_{0}$ ) were obtained from simultaneous adjustments of $\phi$ and $\gamma_{ \pm}$(the mean salt activity coefficient) for the binary solutions of perchlorate salts, $\mathrm{M}\left(\mathrm{ClO}_{4}\right)_{2} \cdot{ }^{15}$ The Pauling diameter was adopted for the chloride anion, $\sigma_{C l^{-}}=3.62 \AA .{ }^{15,16} \mathrm{~A}$ value of $4.53 \AA$ was used for the perchlorate anion diameter, ${ }^{15}$ which is in excellent agreement with the 'thermochemical' value of $4.52 \AA .{ }^{56,57}$

The sizes of the $\mathrm{Zn}^{2+} \ldots \mathrm{Cl}^{-}$and $\mathrm{Ni}^{2+} \ldots \mathrm{Cl}^{-}$ionic complexes were taken as being that of a sphere having the same volume as the two free ions. The diameters of the other $\mathrm{MCl}^{+}$ complexes were obtained using Eq. 17 of ref. I, which should reasonably account for the effect of hydration of the metal cation. In the case of complexes of higher stoichiometry, $\mathrm{MCl}_{n} \mathrm{~W}_{p}{ }^{2-n}$ with $n \geq 2$, it was assumed that the molecule is not substantially further hydrated. This may be expected because the presence of negatively charged chlorides in the complex must greatly reduce the attraction of water molecules to the metal cation. Moreover these chlorides are likely to reduce the local positive electric charge on the central cation (down from +2 ) through electron transfer. ${ }^{35}$ As a consequence of these phenomena, the complexes, $\mathrm{MCl}_{n} \mathrm{~W}_{p}{ }^{2-n}$ for $n \geq 2$, were regarded as spheres and their diameter was also approximated as being that of a sphere having the same volume as the species constituting the complex. A diameter of $2.8 \AA$ was used for the water molecule. ${ }^{58,59}$

\section{Results and discussion}

\section{Solution densities}

The results of this section are presented in the Supplementary Information addendum.

\section{Sizes assigned to the solute species}

The diameters of the free cations $\left(\mathrm{N}^{+}\right.$or $\mathrm{N}^{2+}$, and $\left.\mathrm{M}^{2+}\right)$ at $\mathrm{MM}$ level were determined by fitting simultaneously the osmotic and activity coefficients of strong electrolytes containing the cations, up to ionic strengths of $3 \mathrm{~mol} \mathrm{~L}^{-1}$ and using the MSA formulas of ref. ${ }^{15}$ for 
completely dissociated salts. This limit was the upper bound adopted in ref. I. In the calculations the concentrations were obtained using the solution densities of Table S1 (see Supplementary Information).

The chloride solutions assumed to be strong electrolytes are collected in Table 2. They include $\mathrm{HCl}$, and some alkali $\left(\mathrm{Li}^{+}, \mathrm{Na}^{+}, \mathrm{K}^{+}\right)$and alkaline earth (from $\mathrm{Mg}^{2+}$ to $\mathrm{Ba}^{2+}$ ) chlorides. In the case of divalent cations for which the chloride salts are self-complexing in water, the perchlorate salts of these cations were assumed to be strong electrolytes. This contention is supported by experimental evidence in the case of zinc(II), ${ }^{60}$ cadmium(II), ${ }^{60,61}$ and cobalt(II). ${ }^{62}$ Somewhat in contrast, $\mathrm{Mn}\left(\mathrm{ClO}_{4}\right)_{2}$ has been identified as being maybe slightly associated. ${ }^{60}$ Then thermodynamic data for perchlorates were fitted within the MSA.

The results of the simultaneous fits of $\phi$ and $\gamma_{ \pm}$, yielding values for the free cation diameters, $\sigma_{0}$, are presented in Table 2. A few remarks may be made about these results.

Table 2: Results for the regression of cation diameters, $\sigma_{0}$, in the simultaneous fits of $\phi$ and $\gamma_{ \pm}$for strong binary electrolytes (with $\sigma_{C l^{-}}=3.62 \AA$ and $\sigma_{C l O_{4}^{-}}=4.53 \AA$ ).

\begin{tabular}{lcccc}
\hline Salt & $\sigma_{0} / \AA$ & AARD $(\phi)^{a}$ & AARD $\left(\gamma_{ \pm}\right)^{a}$ & $\sigma_{\text {cryst }}^{b} / \AA$ \\
\hline $\mathrm{HCl}$ & 4.381 & $1.2 \%$ & $2.9 \%$ & - \\
$\mathrm{LiCl}$ & 4.158 & $1.1 \%$ & $2.3 \%$ & 1.80 \\
$\mathrm{NaCl}$ & 3.021 & $1.1 \%$ & $2.3 \%$ & 2.32 \\
$\mathrm{KCl}$ & 2.502 & $1.1 \%$ & $2.1 \%$ & 3.04 \\
$\mathrm{MgCl}_{2}$ & 5.811 & $1.2 \%$ & $1.9 \%$ & 1.72 \\
$\mathrm{CaCl}_{2}$ & 5.388 & $1.4 \%$ & $2.0 \%$ & 2.28 \\
$\mathrm{SrCl}_{2}$ & 5.123 & $1.1 \%$ & $1.4 \%$ & 2.64 \\
$\mathrm{BaCl}$ & 4.672 & $1.2 \%$ & $1.6 \%$ & 2.98 \\
$\mathrm{Mn}_{2}\left(\mathrm{ClO}_{4}\right)_{2}$ & 6.600 & $2.1 \%$ & $4.4 \%$ & $1.62(\mathrm{LS})-1.94(\mathrm{HS})$ \\
$\mathrm{Co}\left(\mathrm{ClO}_{4}\right)_{2}$ & 6.408 & $1.7 \%$ & $3.3 \%$ & $1.58(\mathrm{LS})-1.77(\mathrm{HS})$ \\
$\mathrm{Ni}\left(\mathrm{ClO}_{4}\right)_{2}$ & 6.322 & $1.6 \%$ & $3.0 \%$ & 1.66 \\
$\mathrm{Cu}\left(\mathrm{ClO}_{4}\right)_{2}$ & 6.218 & $1.3 \%$ & $2.4 \%$ & 1.74 \\
$\mathrm{Zn}\left(\mathrm{ClO}_{4}\right)_{2}$ & 6.101 & $1.5 \%$ & $2.8 \%$ & 2.76 \\
$\mathrm{Cd}\left(\mathrm{ClO}_{4}\right)_{2}$ & 5.661 & $1.7 \%$ & $2.9 \%$ & 2.66 \\
$\mathrm{~Pb}\left(\mathrm{ClO}_{4}\right)_{2}$ & 4.939 & $0.9 \%$ & $1.4 \%$ & 0 \\
\hline
\end{tabular}

${ }^{a}$ Average Absolute Relative Deviation; ${ }^{b}$ Crystallographic diameter of cation ${ }^{57}$ (for a coordination number of 6 ) with $\mathrm{LS}=$ low spin, $\mathrm{HS}=$ high spin.

First, the $\sigma_{0}$ values for $\mathrm{Zn}^{2+}$ and $\mathrm{Cd}^{2+}$ are slightly different from those reported in ref. I because in the latter work no MM-to-LR conversion was used for the mean salt activity 
coefficient.

Next, the values of $\sigma_{0}$ decrease when going from $\mathrm{LiCl}$ down to $\mathrm{KCl}$ in the series of alkali metals, from $\mathrm{MgCl}_{2}$ to $\mathrm{BaCl}_{2}$ in that of alkaline earth metals, and from $\mathrm{Mn}\left(\mathrm{ClO}_{4}\right)_{2}$ to $\mathrm{Pb}\left(\mathrm{ClO}_{4}\right)_{2}$. As was noted in ref. ${ }^{15}$ this outcome is very satisfactory because these decreases of $\sigma_{0}$ in the three series are expected at the MM level at which the ion size includes the contribution of the hydration shell. As a consequence the diameters of cations at MM level should be larger than their crystallographic diameter, or nearly equal to it if they are weakly hydrated. For this reason the size of $\mathrm{Cl}^{-}$is taken equal to its crystallographic size because this anion is thought to be nearly unhydrated. ${ }^{63}$ Furthermore a small cation like $\mathrm{Li}^{+}$must be more heavily hydrated, and thus have a larger $\sigma_{0}$ than $\mathrm{Na}^{+}$and $\mathrm{K}^{+}\left(\mathrm{Li}^{+}>\right.$ $\mathrm{Na}^{+}>\mathrm{K}^{+}$) in water at MM level because it carries more water molecules than $\mathrm{Na}^{+}$and $\mathrm{K}^{+}$. The same principle holds for $\sigma_{0}$ in the series $\mathrm{Mg}^{2+}>\mathrm{Ca}^{2+}>\mathrm{Sr}^{2+}>\mathrm{Ba}^{2+}$ because their crystallographic sizes are in reverse order (see last column of Table 2), and in the series $\mathrm{Ni}^{2+}>\mathrm{Cu}^{2+}>\mathrm{Zn}^{2+}>\mathrm{Cd}^{2+}>\mathrm{Pb}^{2+}$.

Another point worth mentioning is that the degree of hydration of a divalent cation should be higher than that of a monovalent cation of the same crystallographic diameter. This principle is verified in Table 2 as may be seen for example in the case of $\mathrm{Li}^{+}, \mathrm{Mg}^{2+}$ and $\mathrm{Zn}^{2+}$, or in the case of $\mathrm{Na}^{+}$and $\mathrm{Ca}^{2+}$, that have comparable crystallographic sizes, and $\sigma_{0}$ is significantly higher for the divalent cations than for the monovalent one.

It is also observed in Table 2 that the AARD of fit of $\phi$ is generally appreciably lower than that of $\gamma_{ \pm}$, with average values of $1.4 \%$ for $\phi$ vs. $2.5 \%$ for $\gamma_{ \pm}$. It is noticed that the AARD's are a bit higher in the case of $\mathrm{Mn}\left(\mathrm{ClO}_{4}\right)_{2}$. However, it should be noticed that for this electrolyte the possibility of a small degree of association was mentioned in a study using Raman spectroscopy. ${ }^{60}$ This fact may be the reason for the higher AARD's of fit found in the case of $\mathrm{Mn}\left(\mathrm{ClO}_{4}\right)_{2}$, if it is regarded as a strong salt.

A last point is the fact that $\sigma_{0}$ for $\mathrm{K}^{+}(\sim 2.5 \AA)$ is a bit smaller than the crystallographic diameter. This shortcoming seems to be due to the fact that the MSA model used here is 
simplified. This did not occur in the more refined model of ref. ${ }^{15}$ in which the cation size and the solution permittivity were taken as being concentration dependent. In this latter version of the model, the $\mathrm{K}^{+}$diameter (at infinite dilution) was $3.45 \AA$ and it remained larger than $\sigma_{\text {cryst }}$ at all concentrations. However it would not be possible to develop a MSA model at the same level as in ref. ${ }^{15}$ for the present topic of mixtures containing self-associating electrolytes, because one would have to introduce dependencies of the two cation diameters (and of the solution permittivity) with the composition of solution. Such a model would be cumbersome and would introduce too many unknown parameters. Therefore one is compelled to use a simplified MSA model, which necessarily may have some shortcoming. So one has to admit that the MSA diameter of $\mathrm{K}^{+}$is small, but since it allows a good description of $\phi$ and $\gamma_{ \pm}$in the case of $\mathrm{KCl}$ solution it will be accepted that this diameter value may be used in the case of mixtures in the present framework.

Then the sizes for the complexes were assessed following the method described in the section about the diameters of species. The values of the $\sigma_{n}$ 's are collected in Table 3 . In the case of $\mathrm{NiCl}_{2}$ only the value of $\sigma_{1}$ is given in the table because no complex of higher stoichiometry had been found in two independent experimental studies. ${ }^{64,65}$

Table 3: Values of the diameters $\sigma_{n}$ (in $\AA$ ) taken for the complexes (with $n$ the number of chlorine atoms in the complex), with $\sigma_{C l^{-}}=3.62 \AA$.

\begin{tabular}{lcccc}
\hline Salt & $\sigma_{1}$ & $\sigma_{2}$ & $\sigma_{3}$ & $\sigma_{4}$ \\
\hline $\mathrm{MnCl}_{2}$ & 6.523 & 5.482 & 5.162 & 5.352 \\
$\mathrm{CoCl}_{2}$ & 6.360 & 5.478 & 5.158 & 5.348 \\
$\mathrm{NiCl}_{2}$ & 6.618 & - & - & - \\
$\mathrm{CuCl}_{2}$ & 6.202 & 5.513 & 5.180 & 5.364 \\
$\mathrm{ZnCl}_{2}$ & 6.418 & 5.495 & 5.177 & 5.366 \\
$\mathrm{CdCl}_{2}$ & 5.751 & 5.549 & 5.237 & 5.422 \\
$\mathrm{PbCl}_{2}$ & 5.134 & 5.658 & 5.343 & 5.516 \\
\hline
\end{tabular}

\section{Results for the $\beta_{n}$ 's}

In this section, wide intervals of $\beta_{n}$ values were explored for each self-complexing salt, and possibly each added salt. Initially, the lower and upper bounds were taken as 1/100 and 
100 times, respectively, typical values found in the literature. For every set of $\beta_{n}$ 's the speciation, the mean coordination number, $N_{C l}$, and the thermodynamic quantities were computed according to the methods depicted in the preceding sections.

A set of values was stored when the AARD on the computed value of $\phi$ or $\gamma_{S}$ (in the case $\mathrm{S}=\mathrm{HCl}$ or $\mathrm{CdCl}_{2}$, see Table 4 or 5 ) for the various compositions was lower than some imposed limit. In view of the results of Table 2 , for most salts this uncertainty was estimated to be of the order of $1.4 \%$ on $\phi$ and $2.5 \%$ on $\gamma_{S}$, which are the mean deviations of these quantities in this table. Thus, (typically a few thousands of) sets of $\beta_{n}$ values that gave an AARD $<1.4 \%$ for $\phi$ or $<2.5 \%$ for $\gamma_{S}$ were recorded. Two exceptions were the case of $\mathrm{NiCl}_{2}$ for which the upper limit was raised to $2 \%$ for $\phi$ because the lowest AARD was found to be $1.5 \%$ as shown below (see Table 4), and that of $\mathrm{PbCl}_{2}$ for which the limit was reduced to $0.9 \%$ because the lowest AARD was $0.36 \%$ for $\phi$ (see Table 4 ).

Let us underline that, in all calculations, thermodynamic measurements concerning pure binary solutions were also included in the data ${ }^{50}$ (in addition to data for ternary solutions).

However, in the case of solutions of $\mathrm{Mn}(\mathrm{II}), \mathrm{Cu}(\mathrm{II})$ and $\mathrm{Zn}(\mathrm{II})$ chlorides, for which experimental speciation-related information is available (Table 1) a set of $\beta_{n}$ 's had to satisfy the additional condition that the calculated $p_{0}$ and $p_{1}$, and/or $N_{C l}$ values were in agreement with experiment, within experimental uncertainty. If not, the set of $\beta_{n}$ 's was discarded.

This first analysis determined sets of 'possible' complexity constants. In the case of $\mathrm{CoCl}_{2}$ and $\mathrm{ZnCl}_{2}$ for which data for two different mixtures are available, the same ranges of $\beta_{n}$ values were explored.

After this scan of $\beta_{n}$ 's was accomplished, the set that gave the best consistency with experimental thermodynamic data, $\phi$ or $\gamma_{S}$, was determined. Actually, in order to assess this 'optimum' set accurately, the intervals of search were subsequently sliced in smaller ones of equal width (on log scale), step by step, until this width reached a value of 0.01 . A scan typically lasted between several hours and two days in the first calculations, and a few minutes in the last stage of the search. 
The results for the 'optimum' sets of complexity constants are presented in Table 4 (decimal logarithms of the $\beta_{n}$ 's). It is seen in this table that the number of $\phi$ or $\gamma_{S}$ data was large for all mixtures, ranging from 23 to 136 . The corresponding results for the speciation and for $N_{C l}$ are shown in Table S2 of the Supplementary Information addendum (see also Table 1).

In a second type of calculation, a statistical analysis of the values of the possible $\beta_{n}$ 's recorded in the first stage was performed. The mean value and the related uncertainties (root mean square deviations) and AARD's (on $\phi$ or $\gamma_{S}$ ) were computed. They are shown in Table 5. It is seen that the AARD's for each mixture are still quite acceptable after averaging the $\beta_{n}$ values.

Table 4: 'Optimum' values for the complex formation constants, $\log _{10} \beta_{n}$.

\begin{tabular}{llcccccccc}
\hline Salt & Added salt & $N^{a}$ & Max. $I^{b}$ & AARD of fit & Ref. & $\beta_{1}{ }^{c}$ & $\beta_{2}{ }^{c}$ & $\beta_{3}{ }^{c}$ & $\beta_{4}{ }^{c}$ \\
\hline $\mathrm{MnCl}_{2}$ & $+\mathrm{NaCl}$ & 73 & $2.4 \mathrm{M}$ & $0.91 \%$ & 66 & 0.52 & -0.36 & $-{ }^{d}$ & $-{ }^{d}$ \\
$\mathrm{CoCl}_{2}$ & $+\mathrm{NaCl}$ & 44 & $2.8 \mathrm{M}$ & $1.0 \%$ & 67 & 0.35 & -0.76 & $-d$ & $-d$ \\
& $+\mathrm{KCl}$ & 23 & $2.3 \mathrm{M}$ & $1.0 \%$ & 68 & 0.19 & -0.37 & ${ }^{d}$ & ${ }^{d}$ \\
$\mathrm{NiCl}_{2}$ & $+\mathrm{NaCl}$ & 40 & $2.8 \mathrm{M}$ & $1.5 \%$ & 68 & 0.33 & $-d$ & $-d$ & $-d$ \\
$\mathrm{CuCl}_{2}$ & $+\mathrm{NaCl}$ & 54 & $2.3 \mathrm{M}$ & $0.81 \%$ & 69 & 0.41 & 0.17 & $-d$ & -3.5 \\
$\mathrm{ZnCl}_{2}$ & $+\mathrm{HCl}$ & 37 & $1.4 \mathrm{M}$ & $1.8 \%$ & 70 & 0.24 & -0.09 & 0.05 & -1.0 \\
& $+\mathrm{BaCl}_{2}$ & 136 & $2.4 \mathrm{M}$ & $1.1 \%$ & 71 & 0.30 & 0.05 & 0.12 & -1.38 \\
$\mathrm{CdCl}_{2}$ & $+\mathrm{NaCl}^{f}$ & 36 & $0.8 \mathrm{M}$ & $1.9 \%$ & 72 & 1.95 & 2.54 & 2.89 & $-d$ \\
$\mathrm{PbCl}_{2}{ }^{g}$ & & 13 & $0.08 \mathrm{M}$ & $0.35 \%$ & 50 & 1.50 & 1.82 & 3.3 & $-d$ \\
\hline
\end{tabular}

${ }^{a}$ Number of data points; ${ }^{b}$ Maximum ionic strength; ${ }^{c}$ Decimal logarithm; ${ }^{d} \beta_{n}=0$; ${ }^{e}$ Measurement of $\gamma_{\mathrm{HCl}} ;{ }^{f}$ Measurement of $\gamma_{\mathrm{CdCl}_{2}} ;{ }^{g}$ Binary solution.

After having determined values for the $\beta_{n}$ 's we now examine the results from the MSA model in the case of pure binary solutions. So, the osmotic coefficient, $\phi$, or the mean salt activity coefficient, $\gamma_{ \pm}$, for the binary solutions obtained using the mean $\beta_{n}$ values of Table 5 or 6 (see below) are shown in Figures 1-8 (in which the size of the symbols is about the experimental uncertainty of $\sim 1 \%$ ).

These results are now discussed for each salt. 
Table 5: Mean values for the complexity constants, $\log _{10} \beta_{n}$.

\begin{tabular}{llccccc}
\hline Salt & Added salt & $\log _{10} \beta_{1}$ & $\log _{10} \beta_{2}$ & $\log _{10} \beta_{3}$ & $\log _{10} \beta_{4}$ & AARD \\
\hline $\mathrm{MnCl}_{2}$ & $+\mathrm{NaCl}$ & $0.46 \pm 0.04$ & $-0.36 \pm 0.06$ & $-^{b}$ & $-^{b}$ & $1 \%$ \\
$\mathrm{CoCl}_{2}$ & $+\mathrm{NaCl}$ & $0.29 \pm 0.06$ & $-0.67 \pm 0.12$ & $-^{b}$ & $-{ }^{b}$ & $1.1 \%$ \\
& $+\mathrm{KCl}$ & $0.17 \pm 0.09$ & $-0.35 \pm 0.09$ & $-^{b}$ & $-{ }^{b}$ & $1.4 \%$ \\
$\mathrm{NiCl}_{2}$ & $+\mathrm{NaCl}$ & $0.31 \pm 0.07$ & $-b$ & $-^{b}$ & $-^{b}$ & $1.5 \%$ \\
$\mathrm{CuCl}_{2}$ & $+\mathrm{NaCl}$ & $0.43 \pm 0.02$ & $0.16 \pm 0.02$ & $-^{b}$ & $-3.7 \pm 0.5$ & $0.8 \%$ \\
$\mathrm{ZnCl}_{2}$ & $+\mathrm{HCl}^{c}$ & $0.10 \pm 0.09$ & $0.17 \pm 0.12$ & $0.14 \pm 0.06$ & $-1.4 \pm 0.5$ & $1.8 \%$ \\
& $+\mathrm{BaCl}_{2}$ & $0.20 \pm 0.08$ & $0.15 \pm 0.11$ & $0.12 \pm 0.08$ & $-1.5 \pm 0.4$ & $1.1 \%$ \\
$\mathrm{CdCl}_{2}$ & $+\mathrm{NaCl}^{d}$ & $1.94 \pm 0.02$ & $2.55 \pm 0.06$ & $2.88 \pm 0.08$ & $-{ }^{b}$ & $2 \%$ \\
$\mathrm{PbCl}_{2}{ }^{a}$ & & $1.50 \pm 0.03$ & $1.90 \pm 0.06$ & $3.3 \pm 0.2$ & $-^{b}$ & $0.4 \%$ \\
\hline
\end{tabular}

${ }^{a}$ Binary solution; ${ }^{b} \beta_{n}=0 ;{ }^{c}$ Measurement of $\gamma_{H C l} ;{ }^{d}$ Measurement of $\gamma_{C d C l_{2}}$.

\section{Case of $\mathrm{MnCl}_{2}$}

Ref. ${ }^{21}$ gives a value for the first complexity constant only, namely $\log _{10} \beta_{1} \sim 0$. It was found in a PhD thesis of 1947. This work does not seem to have been published. No value for the thermodynamic complexity constants (or, equivalently, the constants at infinite dilution) can be found in ref. ${ }^{25}$

Figure 1 shows that the MSA model describes very well the osmotic coefficient of $\mathrm{MnCl}_{2}$ solution up to $1.5 \mathrm{~mol} \mathrm{~kg}^{-1}$, although some deviation is observed at low concentrations (around $0.1 \mathrm{~mol} \mathrm{~kg}^{-1}$ ) which may be due in part to a known inaccuracy of the MSA in

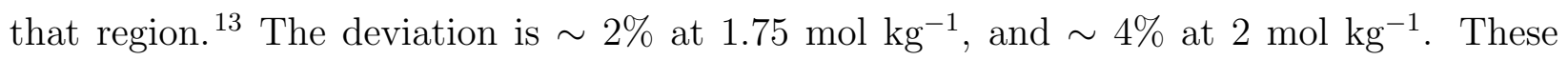
increasing discrepancies are very likely due to the fact that the assumptions of constant solution permittivity and constant ionic diameters become unrealistic (and unsuitable) when the concentration is increased. ${ }^{15,54}$ However the overall representation of $\phi$ is satisfactory with an AARD of $1 \%$ with the $\beta_{n}$ 's of Table 5 .

\section{Case of $\mathrm{CoCl}_{2}$}

Refs. ${ }^{21}$ and ${ }^{25}$ give $\log _{10} \beta_{1}=-1.1$, and $\log _{10} \beta_{2}=-1.28$ and -3.95 , respectively.

Two different sets of values for $\beta_{1}$ and $\beta_{2}$ are given in Table 5 for the two added salts $\mathrm{NaCl}$ and $\mathrm{KCl}$, for which experimental data were obtained by two different groups. The two 


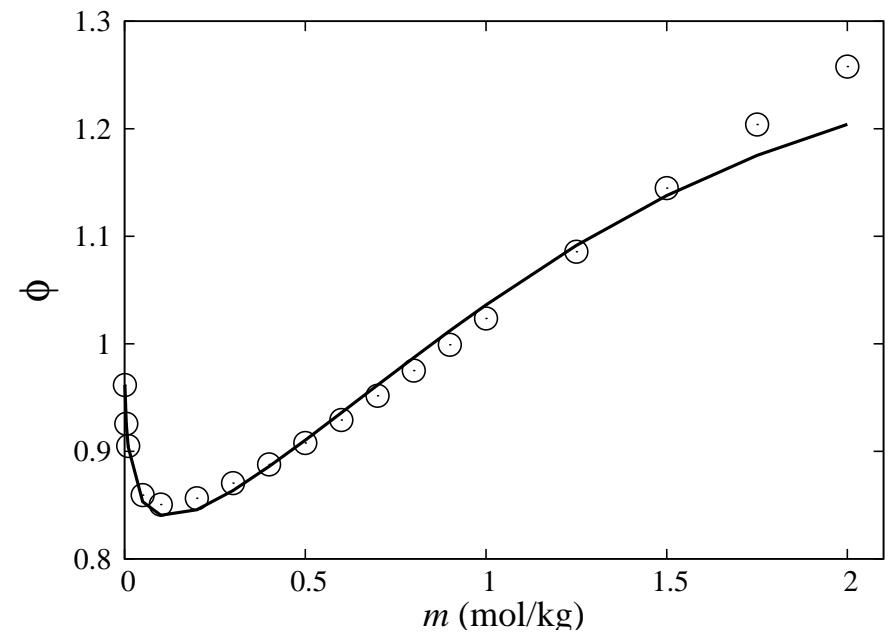

Figure 1: Result for the osmotic coefficient, $\phi$, of $\mathrm{MnCl}_{2}$ as a function of molality computed with the $\beta_{n}$ values of Table 5. (९) Experimental data; ${ }^{50}$ solid line: result from MSA model.

sets are in quite reasonable agreement.

By combining the results for $\beta_{1}$ and $\beta_{2}$ for the two added salts one gets the final values shown in Table 6. With these values the AARD on $\phi$ remains satisfactory. Although some accuracy is inevitably lost upon averaging, they do not lead to a bad description of the osmotic coefficient.

Table 6: Final values for the complexity constants of $\mathrm{CoCl}_{2}$ and $\mathrm{ZnCl}_{2}$.

\begin{tabular}{llcccc}
\hline Salt & $\log _{10} \beta_{1}$ & $\log _{10} \beta_{2}$ & $\log _{10} \beta_{3}$ & $\log _{10} \beta_{4}$ & $\mathrm{AARD}^{a}$ \\
\hline $\mathrm{CoCl}_{2}$ & $0.23 \pm 0.10$ & $-0.52 \pm 0.19$ & $-b$ & $-b$ & $1.3 \%$ \\
$\mathrm{ZnCl}_{2}$ & $0.12 \pm 0.10$ & $0.17 \pm 0.12$ & $0.14 \pm 0.07$ & $-1.4 \pm 0.4$ & $1.5 \%$ \\
\hline
\end{tabular}

${ }^{a}$ Mean AARD for the two different mixtures (see Table 5 ); ${ }^{b} \beta_{n}=0$.

The MSA result for $\phi$ in the case of the binary solution is in particularly good agreement with the experimental data as may be seen in Figure 2, although a notable discrepancy occurs around $0.1 \mathrm{~mol} \mathrm{~kg}{ }^{-1}$ (see previous section for $\mathrm{MnCl}_{2}$ ). 


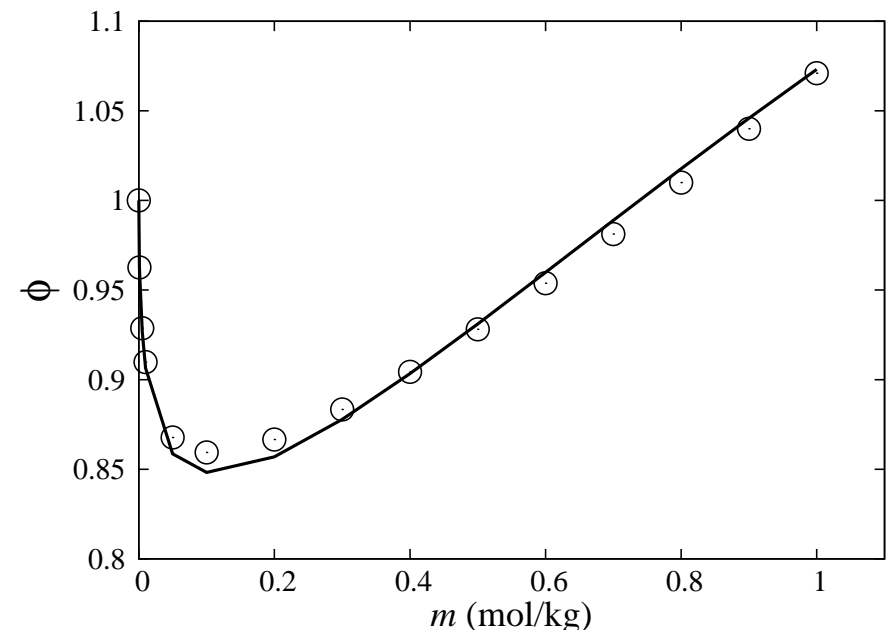

Figure 2: Result for the osmotic coefficient, $\phi$, of $\mathrm{CoCl}_{2}$ as a function of molality computed with the $\beta_{n}$ values of Table 6 . (๑) Experimental data; ${ }^{50}$ solid line: result from MSA model.

\section{Case of $\mathrm{NiCl}_{2}$}

Refs. $^{21}$ and $^{25}$ report no value for the thermodynamic complexity constants (i.e. $\beta_{n}$ 's at infinite dilution).

In the present study, only the first complexity constant $\beta_{1}$ was taken into account in the case of $\mathrm{Ni}(\mathrm{II})$, in conformity with experimental observations. ${ }^{64,65}$ An ionic complex was assumed for $\mathrm{NiCl}^{+}$because no chloride had been found in the first coordination shell of Ni. ${ }^{34,37-40}$ The value found here, $\log _{10} \beta_{1}=0.31 \pm 0.07$, should be reliable because this only unknown parameter was regressed in the calculation.

The plot of $\phi$ in Figure 3 reveals that, overall, the MSA model satisfactorily describes the experimental data, although some discrepancy begins to appear at the highest concentrations and a deviation is observed around $0.1 \mathrm{~mol} \mathrm{~kg}^{-1}$ (see section for the case of $\mathrm{MnCl}_{2}$ ).

The deviation is $\sim 4.7 \%$ at $1.5 \mathrm{~mol} \mathrm{~kg}{ }^{-1}$. 


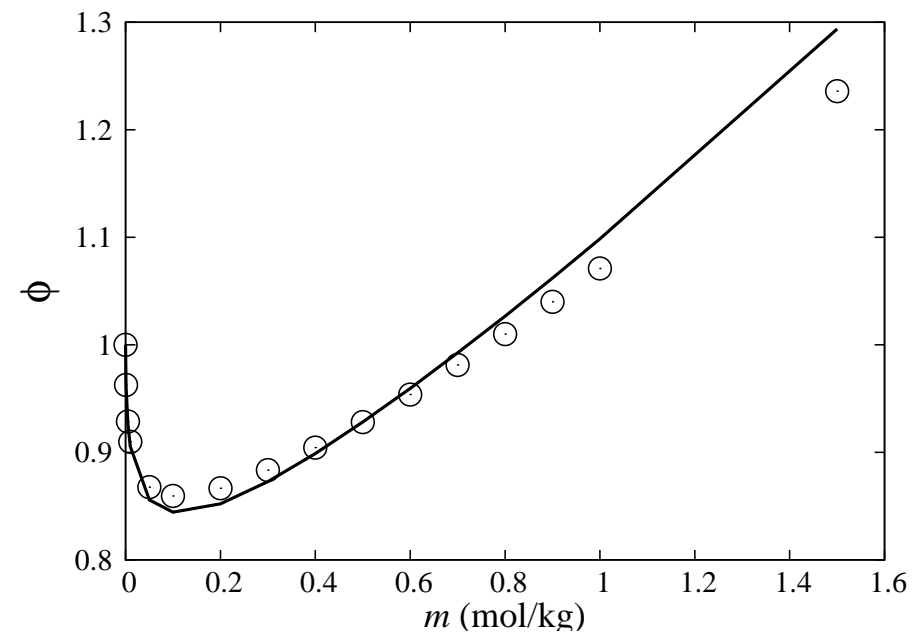

Figure 3: Result for the osmotic coefficient, $\phi$, of $\mathrm{NiCl}_{2}$ as a function of molality computed with the $\beta_{n}$ values of Table 5. (९) Experimental data; ${ }^{50}$ solid line: result from MSA model.

\section{Case of $\mathrm{CuCl}_{2}$}

Values for $\log _{10} \beta_{1}$ ranging from 0.05 to 0.4 may be found in the critical tables. ${ }^{21,25} \mathrm{~A}$ more recent work of Powell et al. ${ }^{28}$ proposed the value $\log _{10} \beta_{1}=0.83 \pm 0.09$. The value found here, $0.43 \pm 0.02$, is at the high end of the range of values from the first source and below that of the second one.

As regards the other constants only a value for $\beta_{2}$ was given in the same work: ${ }^{28} \log _{10} \beta_{2}=$ $0.6 \pm 0.3$. No value for the other constants is available in the literature. Here we obtained $\log _{10} \beta_{2}=0.16 \pm 0.02$, which is lower than that of Powell et al. but of the same order of magnitude.

For the other constants we get $\beta_{3}=0$ and $\log _{10} \beta_{4}=-3.7 \pm 0.5$. The uncertainty on the value of $\beta_{4}$ might actually be larger because very little amounts of the fourth complex were found in the calculation (maximum value of $p_{4} \sim 0.03$ ).

The result from the MSA model for $\phi$ in the case of pure binary $\mathrm{CuCl}_{2}$ solution with the $\beta_{n}$ values of Table 5 in Figure 4 is good up to $1.5 \mathrm{~mol} \mathrm{~kg}^{-1}$. Above, it deviates more and more from experiment (see section for $\mathrm{MnCl}_{2}$ ). The maximum deviation is of $\sim 2 \%$ at 2 mol 
$\mathrm{kg}^{-1}$.

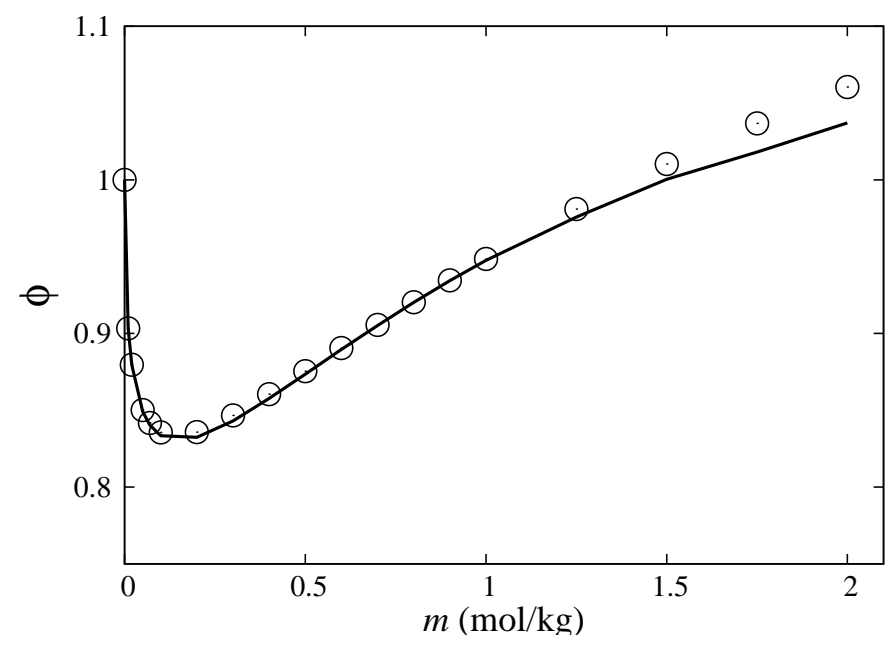

Figure 4: Result for the osmotic coefficient, $\phi$, of $\mathrm{CuCl}_{2}$ as a function of molality computed with the $\beta_{n}$ values of Table 5. (९) Experimental data; ${ }^{50}$ solid line: result from MSA model.

\section{Case of $\mathrm{ZnCl}_{2}$}

Thermodynamic data for two mixtures containing $\mathrm{ZnCl}_{2}$ were retrieved from the literature. Different quantities were measured for these two different mixtures, namely activity coefficient values $\gamma_{\mathrm{HCl}}$ for added $\mathrm{HCl}$, and osmotic coefficient values $\phi$ for added $\mathrm{BaCl}_{2}$.

The first important remark in the case of $\mathrm{ZnCl}_{2}$ is that attempts of calculations with $n_{0}=2$, i.e. assuming that $\mathrm{ZnCl}^{+}$is an outer-sphere ion pair, were unsuccessful. No $\beta_{n}$ values could be found that gave AARD's of fit below the limits imposed $(<1.4 \%$ for $\phi$ or $<2.5 \%$ for $\gamma_{H C l}$ together with satisfactory $p_{0}, p_{1}$ and $N_{C l}$ values). The origin of this unexpected result is difficult to ascertain. Various possibilities may be mentioned, such as the first $\mathrm{ZnCl}^{+}$complex being (totally or partly) an inner-sphere complex instead of an outer-sphere ionic complex, inaccuracies in the values of $p_{0}, p_{1}$ or $N_{C l}$, or the existence of an additional phenomenon of unknown nature. Let us notice that the latter possibility is not quite unlikely in view of the many peculiarities exhibited by zinc chloride solutions. ${ }^{22,23}$ 
In the face of these uncertainties, it was assumed that the monochloro complex is not ionic but covalent (inner-sphere $\mathrm{ZnCl}^{+}$complex). The value $n_{0}=1$ was taken in eq. 3 for the two added salts $\mathrm{HCl}$ and $\mathrm{BaCl}_{2}$, and the two conditions on the value of $p_{1}$ (see Table 1) were relaxed because the estimation of $p_{1}$ included the hypothesis of an ionic complex. The diameter of the first complex was now $\sigma_{1}=6.104 \AA$.

The results from this procedure are given in Table 5 . One notices in this table that the confidence intervals for the two sets of $\beta_{n}$ values in Table 5 do overlap. Combination of the results for the $\beta_{n}$ 's for the two added salts leads to values given in Table 6 .

Values for the complexity constants may be found in the critical tables ${ }^{21,25}$ (mostly taken from the work of Marcus ${ }^{73}$ from which uncertainties may be estimated as mentioned in ref. I) and from a recent work. ${ }^{31}$ From these sources we get: $\log _{10} \beta_{1} \sim 0.4 \pm 0.2, \log _{10} \beta_{2} \sim 0.6 \pm 0.3$, $\log _{10} \beta_{3} \sim 0.5 \pm 0.5$, and $\log _{10} \beta_{4} \sim 0.2 \pm 0.2$. The last value is however highly uncertain as pointed out by Powell et al. ${ }^{31}$ and should not be retained according to this last reference.

The results from this work (Table 5) are compatible with literature values but at the lower end of their confidence intervals as may be seen in Figure 5.

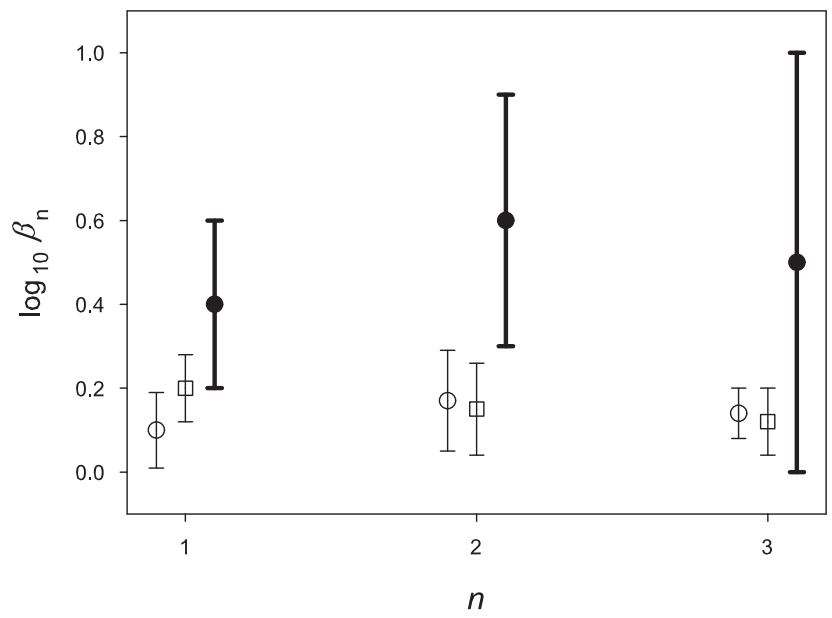

Figure 5: Values for the $\beta_{n}$ 's in the case of $\mathrm{ZnCl}_{2}$ for $n=1,2,3:(\odot)$ Values found in this work in the case of mixtures with $\mathrm{HCl}$, and $(\square)$ in the case of $\mathrm{BaCl}_{2}$ added salt; (•) Literature values. ${ }^{21,25,31}$ 
We note that, in the present computations, appreciable quantities of the third and fourth complexes are formed when the added salt concentration is much larger than that of $\mathrm{ZnCl}_{2}$. The maximum proportions of these complexes in mixtures with $\mathrm{HCl}$ and $\mathrm{BaCl}_{2}$ were $p_{3}^{\max } \sim$ 0.31 and 0.49 , and $p_{4}^{\max } \sim 0.23$ and 0.34 , respectively. Moreover in these cases the calculated $\phi$ or $\gamma_{\mathrm{HCl}}$ is often in good agreement with the experimental measurement. Consequently the result for $\phi$ or $\gamma_{H C l}$ is sensitive to the values of $\beta_{3}$ and $\beta_{4}$ when the amount of chloride is much larger than that of $\mathrm{Zn}(\mathrm{II})$.

The MSA result with the $\beta_{n}$ 's of Table 6 (denoted as set 1) and that using Smith and Martell values ${ }^{25}$ (set 2) are plotted in Figure 6. The latter values from Smith and Martell are: $\log _{10} \beta_{n}=0.46,0.60,0.50$ and 0.20 for $n=1, \ldots, 4$, respectively.

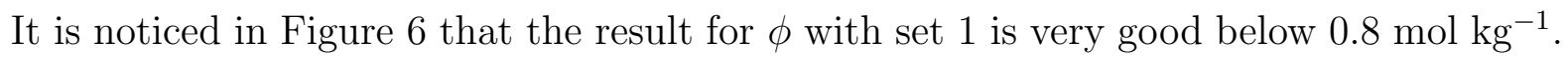
Above this concentration it deviates from the experimental data, gradually to the downside. The deviation is $\sim-4.7 \%$ at $1.5 \mathrm{~mol} \mathrm{~kg}{ }^{-1}$.

However it is much better than the plot corresponding to set 2 (the dashed line in Figure 6). The result found using set 2 follows experimental data up to a low concentration of $\sim 0.05 \mathrm{~mol} \mathrm{~kg}^{-1}$. The discrepancy from the experimental data at $1.5 \mathrm{~mol} \mathrm{~kg} \mathrm{~kg}^{-1}$ reaches $-23 \%$. This deviation is similar to that found in ref. I for the mean salt activity coefficient when deviations from ideality were computed using the (inaccurate) Davies equation or the SIT model and $\beta_{n}$ sets of values taken from the literature.

As was found in ref. I, these results suggest that the classic $\beta_{n}$ values give thermodynamic quantities $\left(\phi\right.$ or $\left.\gamma_{S}\right)$ that are not consistent with experimental data in the case of $\mathrm{ZnCl}_{2}$ solution.

\section{Case of $\mathrm{CdCl}_{2}$}

The case of cadmium chloride is simpler than the previous one because it gives rise to stronger complexes. The recommended values from ref. ${ }^{25}$ are $\log _{10} \beta_{1}=1.98 \pm 0.03, \log _{10} \beta_{2}=$ $2.6 \pm 0.1, \log _{10} \beta_{3}=2.4 \pm 0.1$ and $\log _{10} \beta_{4}=1.7$. The values of Powell et al. ${ }^{30}$ for $\beta_{1}, \beta_{2}$ 


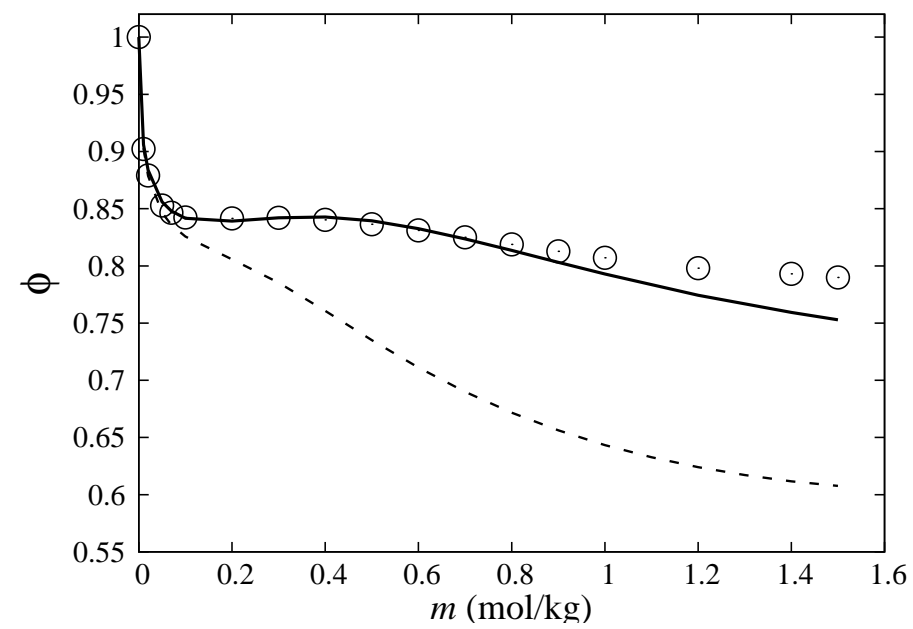

Figure 6: Result for the osmotic coefficient, $\phi$, of $\mathrm{ZnCl}_{2}$ solution as a function of molality. (○) Experimental data; ${ }^{50}$ solid line: result from MSA model with the $\beta_{n}$ 's of Table 6 ; dashed line: result from MSA model computed with the $\beta_{n}$ values of Smith and Martell. ${ }^{25}$

and $\beta_{3}$ are very close to these latter values (no value was proposed for $\beta_{4}$ because of the high uncertainty on constant). The values found in this work (Tables 4 and 5) for $\beta_{1}$ and $\beta_{2}$ are in keeping with the literature values. Our value for $\beta_{3}, \log _{10} \beta_{3} \sim 2.9$, is a bit larger. Here we find, $\beta_{4}=0$, that is no complex of order 4 . As pointed out in ref. ${ }^{30}$ the constant proposed by Smith and Martell is quite uncertain.

As already mentioned in ref. I, the first complex is rather strong (rather high complexity constant $\beta_{1}$ ). Consequently the behavior of the binary solution at low concentration is governed by the effect of this first complex, and there is therefore very little uncertainty on the value of $\beta_{1}$ whatever the model used to determine it (as long as the model is equivalent to DH theory at low concentration). This is also true for the second complex.

Figure 7 shows that the MSA result reproduces very well the experimental values for $\gamma_{ \pm}$ in pure binary solution with the $\beta_{n}$ 's of Table 5 . At $1.5 \mathrm{~mol} \mathrm{~kg}^{-1}$ the mean activity coefficient of $\mathrm{CdCl}_{2}$ is very low $\left(\gamma_{ \pm} \sim 0.05\right)$ because of the strong association. 


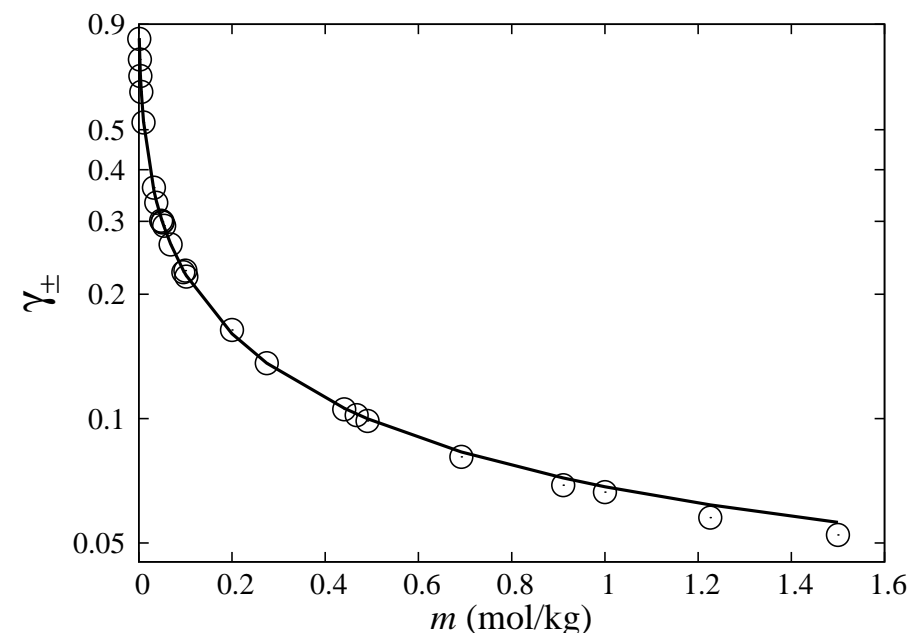

Figure 7: Result for the mean salt activity coefficient, $\gamma_{ \pm}$(log-scale), of $\mathrm{CdCl}_{2}$ as a function of molality computed with the $\beta_{n}$ values of Table 5 . (९) Experimental data; ${ }^{50}$ solid line: result from MSA model.

\section{Case of $\mathrm{PbCl}_{2}$}

The values for the constants reported in the critical tables ${ }^{21,25}$ are in the following ranges: 1.1 $1.62,1.78-2.44,1.4-1.86$ and $0.81-1.4$, for $n=1, \ldots, 4$ respectively. More recent studies ${ }^{29,74}$ report $\log _{10} \beta_{1}=1.5, \log _{10} \beta_{2} \sim 2$ and $2.1, \log _{10} \beta_{3} \sim 2$, and no fourth complex, $\beta_{4}=0$ as found previously. ${ }^{75}$

The values found here (see Table 5 ), $\log _{10} \beta_{1} \sim 1.5$ and $\log _{10} \beta_{2} \sim 1.9$, and $\beta_{4}=0$ are in keeping with these latter values. The value of the first complexity constant is likely to be accurate because the first complex is rather strong. At the low maximum concentration of $0.039 \mathrm{~mol} \mathrm{~kg}^{-1}$ (which corresponds to saturation), the high calculated proportion of the first complex, $p_{1}^{\max } \sim 0.37$, guarantees that the model is sensitive to $\beta_{1}$. In contrast, for the second complex at saturation we find $p_{2} \sim 0.033$, which is likely insufficient to ensure a good accuracy in the determination of $\beta_{2}$.

Our value for the third complexity constant $\left(\log _{10} \beta_{3} \sim 3.3\right)$ is larger than the literature values. However, since $p_{3} \sim 0.046$ at saturation, the actual uncertainty on $\beta_{3}$ must be rather 
high.

The low solubility of $\mathrm{PbCl}_{2}$ in water at $25^{\circ} \mathrm{C}$ cannot allow us to assess these constants accurately. Data for mixtures with a chloride salt would be needed to be able to reach the constants $\beta_{2}$ and $\beta_{3}$ reliably. Such data seem to be unavailable at present time.

It is seen in Figure 8 that the osmotic coefficient, $\phi$, computed from the MSA model with the $\beta_{n}$ values of Table 5 is in very good accord with the experimental data.

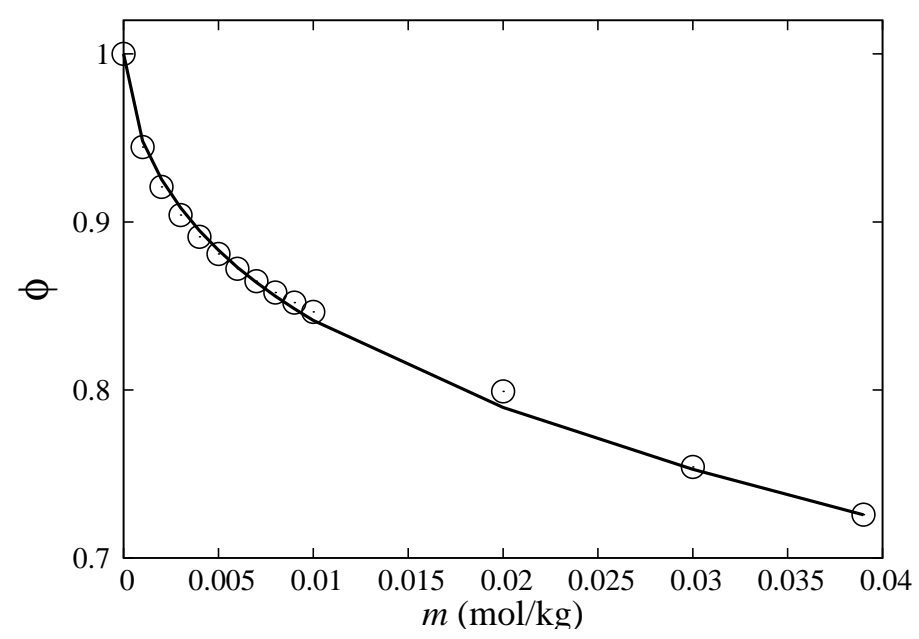

Figure 8: Result for the osmotic coefficient, $\phi$, of $\mathrm{PbCl}_{2}$ as a function of molality with the $\beta_{n}$ values of Table 5. (९) Experimental data; ${ }^{50}$ solid line: result from MSA model.

\section{Sensitivity of results to the diameters of the complexes}

The sensitivity of the above results for the $\beta_{n}$ 's w.r.t. the sizes of the complexes was examined by varying their diameters by $\pm 5 \%$. The variation was made for one complex at a time.

This modification had nearly no effect in the case of $\mathrm{CdCl}_{2}$ or $\mathrm{PbCl}_{2}$ because the maximum ionic strength was rather low for the first salt $(0.8 \mathrm{M})$ and very low for the second $(0.08 \mathrm{M})$. It was reduced in the case of the mixture $\mathrm{ZnCl}_{2}+\mathrm{HCl}$.

This was not so for the other salts where the ionic strength was of $2.4 \mathrm{M}$ or $2.8 \mathrm{M}$. This is because the hard sphere parts of the osmotic and activity coefficients vary rapidly with 
the size of the species (see, e.g., Eq. 5). At the highest ionic strengths it was observed that the values of $\log _{10} \beta_{n}$ varied by $\sim \pm 0.1$ on average when the diameter of a complex was individually varied by $5 \%$, with variations in the range of 0.02 to 0.18 .

\section{Conclusion}

Values for the complexity constants of the divalent cations $\mathrm{Mn}^{2+}, \mathrm{Co}^{2+}, \mathrm{Ni}^{2+}, \mathrm{Cu}^{2+}, \mathrm{Zn}^{2+}$, $\mathrm{Cd}^{2+}$, and $\mathrm{Pb}^{2+}$, with the chloride anion have been determined from thermodynamic and speciation data. The thermodynamic data consisted of values for the osmotic coefficient $\phi$ or the mean activity coefficient $\gamma_{S}$, for binary solutions of these self-complexing salts and for mixtures with strong salts in water. The speciation-related data included proportions of free cation and first complex, and mean metal-chlorine coordination number.

The MSA model was employed to describe the thermodynamic properties of these ionic solutions. The simplest version of this model has been used in which the solute species have a fixed diameter and the permittivity of solution is that of pure water. The diameters of the species were assessed from their structure. The study was limited to ionic strengths below 3M. In this framework the complexity constants are the only unknown parameters.

In order to be able to consider higher ionic strengths, a natural extension of the present model would be to introduce concentration dependencies for the solution permittivity and

for the diameters of the ionic species, as has been done before. ${ }^{15,16,76}$ The main difficulty in the present work is that many ionic species are present. This would therefore introduce many unknown parameters (at least 5 already for a binary solution), which would make the model hardly tractable in practice. Nevertheless it might be proposed to use empirical formulas for the parameters. This possibility should be examined in future work.

In the present study, the thermodynamic properties and speciation data (when available) could be described consistently for all salts, except in the case of $\mathrm{ZnCl}_{2}$ for which no satisfactory result could be found when the first complex was assumed to be ionic. Alternatively 
the $\mathrm{ZnCl}^{+}$pair was supposed to be an inner-sphere covalent complex, in which case sets of $\beta_{n}$ values could be determined.

The exception of $\mathrm{ZnCl}_{2}$ in this work reminds one of the peculiarities that have long been observed experimentally when measuring the thermodynamic and the transport properties of

this electrolyte. ${ }^{22,23}$ It is the view of the present author that the structure of $\mathrm{ZnCl}_{2}$ aqueous solutions is still not well known. It is not unlikely that some unknown phenomenon is at work in these solutions, that remains to be discovered.

\section{ASSOCIATED CONTENT}

\section{Supporting Information}

The Supporting Information is available free of charge on the ACS Publications website at DOI:...

Calculation of concentrations and partial molar volumes; Results for solution densities; Results for the proportion of free cation, $p_{0}$, and for $N_{C l}$.

\section{References}

(1) Brezonik, P.; Arnold, W. Water chemistry: an introduction to the chemistry of natural and engineered aquatic systems; Oxford University Press, 2011.

(2) Kola, H.; Wilkinson, K. J. Cadmium Uptake by a Green Alga Can Be Predicted by Equilibrium Modelling. Environ. Sci. Technol. 2005, 39, 3040-3047.

(3) Markich, S. J.; Brown, P. L.; Jeffree, R. A.; Lim, R. P. The Effects of pH and Dissolved Organic Carbon on the Toxicity of Cadmium and Copper to a Freshwater Bivalve: Further Support for the Extended Free Ion Activity Model. Arch. Environ. Contam. Toxicol. 2003, 45, 479-491. 
(4) MINTEQ, Program developed in the U.S. (MINTEQA2) and in Sweden (Visual MINTEQ). https://vminteq.lwr.kth.se/.

(5) CHESS, Program developed in France. http://chess.geosciences.mines-paristech.fr/.

(6) SPECIATION, version 3.2, The IUPAC Stability Constants Database, SC-Database and Mini-SCDatabase. 2002; Academic Software, UK, http://www.acadsoft.co.uk.

(7) MINEQL+, Program developed in the US. http://www.mineql.com.

(8) PHREEQC Interactive version 3, free program developed at US Geological Survey (USGS). https://wwwbrr.cr.usgs.gov/projects/GWC_coupled/phreeqc/.

(9) Verweij, W. CHEAQS, Program developed in the Netherlands. http://www.cheaqs.eu/.

(10) Davies, C. W. The extent of dissociation of salts in water. Part VIII. An equation for the mean ionic activity coefficient of an electrolyte in water, and a revision of the dissociation constants of some sulphates. J. Chem. Soc. 1938, 2093-2098.

(11) Guggenheim, E. The specific thermodynamic properties of aqueous solutions of strong electrolytes. Phil. Mag. 1935, 19, 588-643.

(12) Simonin, J.-P. Thermodynamic consistency in the modeling of speciation in selfcomplexing electrolytes. Ind. Eng. Chem. Res. 2017, 56, 9721-9733.

(13) Blum, L. In Theoretical Chemistry; Eyring, H., Henderson, D., Eds.; Academic Press: New York, 1980; pp 1-66.

(14) Blum, L.; Høye, J. Mean spherical model for asymmetric electrolytes. 2. Thermodynamic properties and the pair correlation function. J. Phys. Chem. 1977, 81, 1311-1316.

(15) Simonin, J.-P. Real Ionic Solutions in the Mean Spherical Approximation. 2. Pure Strong Electrolytes up to Very High Concentrations, and Mixtures, in the Primitive Model. J. Phys. Chem. B 1997, 101, 4313-4320. 
(16) Simonin, J.-P.; Bernard, O.; Blum, L. Real ionic solutions in the mean spherical approximation. 3. Osmotic and activity coefficients for associating electrolytes in the primitive model. J. Phys. Chem. B 1998, 102, 4411-4417.

(17) Ruas, A.; Moisy, P.; Simonin, J.-P.; Bernard, O.; Dufrêche, J.-F.; Turq, P. Lanthanide salts solutions: Representation of osmotic coefficients within the binding mean spherical approximation. J. Phys. Chem. B 2005, 109, 5243-5248.

(18) Pailthorpe, B. A.; Mitchell, D. J.; Ninham, B. W. Ion-solvent interactions and the activity coefficients of real electrolyte solutions. J. Chem. Soc. Faraday Trans. 2 1984, 80, 115-139.

(19) Ruaya, J.; Seward, T. The stability of chlorozinc(II) complexes in hydrothermal solutions up to $350^{\circ} \mathrm{C}$. Geochim. Cosmochim. Acta 1986, 50,651-661.

(20) Anderson, A. J.; Mayanovic, R. A.; Bajt, S. A microbeam XAFS study of aqueous chlorozinc complexing to $430^{\circ} \mathrm{C}$ in fluid inclusions from the Knaumuehle granitic pegmatite, Saxonian granulite massif, Germany. Can. Mineral. 1998, 36, 511-524.

(21) Sillen, L. G.; Martell, A. E. Stability constants of metal-ion complexes. Section 1; London Chemical Society, 1964.

(22) Irish, D.; McCarroll, B.; Young, T. Raman study of zinc chloride solutions. J. Chem. Phys. 1963, 39, 3436-3444.

(23) Weingaertner, H.; Mueller, K.; Hertz, H.; Edge, A.; Mills, R. Unusual behavior of transport coefficients in aqueous solutions of zinc chloride at $25^{\circ} \mathrm{C}$. J. Phys. Chem. 1984, 88, 2173-2178.

(24) Robinson, R.; Stokes, R. Electrolyte Solutions; Butterworths, 1968.

(25) Martell, A. E.; Smith, R. M. Critical Stability Constants: First Supplement; Springer Science \& Business Media, 2013; Vol. 4 and 5. 
(26) Smith, R.; Martell, A.; Motekaitis, R. NIST Database 46 Version 8.0, Critically Selected Stability Constants of Metal Complexes. 2004; http://www.nist.gov/srd/nist46.cfm.

(27) Powell, K. J.; Brown, P. L.; Byrne, R. H.; Gajda, T.; Hefter, G.; Sjöberg, S.; Wanner, H. Chemical speciation of environmentally significant heavy metals with inorganic ligands. Part 1: The $\mathrm{Hg}^{2+}+\mathrm{OH}^{-}, \mathrm{Cl}^{-}, \mathrm{CO}_{3}^{2-}, \mathrm{SO}_{4}^{2-}$, and $\mathrm{PO}_{4}^{3-}$ aqueous systems (IUPAC Technical Report). Pure Appl. Chem. 2005, r7, 739-800.

(28) Powell, K. J.; Brown, P. L.; Byrne, R. H.; Gajda, T.; Hefter, G.; Sjöberg, S.; Wanner, H. Chemical speciation of environmentally significant metals with inorganic ligands Part 2: The $\mathrm{Cu}^{2+}-\mathrm{OH}^{-}, \mathrm{Cl}^{-}, \mathrm{CO}_{3}^{2-}, \mathrm{SO}_{4}^{2-}$, and $\mathrm{PO}_{4}^{3-}$ systems (IUPAC Technical Report). Pure Appl. Chem. 2007, 79, 895-950.

(29) Powell, K. J.; Brown, P. L.; Byrne, R. H.; Gajda, T.; Hefter, G.; Leuz, A.-K.; Sjöberg, S.; Wanner, H. Chemical speciation of environmentally significant metals with inorganic ligands. Part 3: The $\mathrm{Pb}^{2}++\mathrm{OH}^{-}, \mathrm{Cl}^{-}, \mathrm{CO}_{3}^{2-}, \mathrm{SO}_{4}^{2-}$, and $\mathrm{PO}_{4}^{3-}$ systems (IUPAC Technical Report). Pure Appl. Chem. 2009, 81, 2425-2476.

(30) Powell, K. J.; Brown, P. L.; Byrne, R. H.; Gajda, T.; Hefter, G.; Leuz, A.-K.; Sjöberg, S.; Wanner, H. Chemical speciation of environmentally significant metals with inorganic ligands. Part 4: The $\mathrm{Cd}^{2+}+\mathrm{OH}^{-}, \mathrm{Cl}^{-}, \mathrm{CO}_{3}^{2-}, \mathrm{SO}_{4}^{2-}$, and $\mathrm{PO}_{4}^{3-}$ systems (IUPAC Technical Report). Pure Appl. Chem. 2011, 83, 1163-1214.

(31) Powell, K. J.; Brown, P. L.; Byrne, R. H.; Gajda, T.; Hefter, G.; Leuz, A.-K.; Sjöberg, S.; Wanner, H. Chemical speciation of environmentally significant metals with inorganic ligands. Part 5: The $\mathrm{Zn}^{2+}+\mathrm{OH}^{-}, \mathrm{Cl}^{-}, \mathrm{CO}_{3}^{2-}, \mathrm{SO}_{4}^{2-}$, and $\mathrm{PO}_{4}^{3-}$ systems (IUPAC Technical Report). Pure Appl. Chem. 2013, 85, 2249-2311.

(32) Powell, K. J.; Brown, P. L.; Byrne, R. H.; Gajda, T.; Hefter, G.; Leuz, A.-K.; Sjöberg, S.; Wanner, H. Chemical Speciation of Environmentally Significant Metals: 
An IUPAC contribution to reliable and rigorous computer modelling. Chemistry International 2015, 37, 15-19.

(33) Ohtaki, H.; Radnai, T. Structure and dynamics of hydrated ions. Chem. Rev. 1993, 93, 1157-1204.

(34) Lagarde, P.; Fontaine, A.; Raoux, D.; Sadoc, A.; Migliardo, P. EXAFS studies of strong electrolytic solutions. J. Chem. Phys. 1980, 72, 3061-3069.

(35) Morris, D.; Short, E. L.; Waters, D. Zinc chloride and zinc bromide complexes - III Structures of species in solution. J. Inorg. Nucl. Chem. 1963, 25, 975-983.

(36) Kaatze, U.; Lönnecke, V.; Pottel, R. Dielectric spectroscopy on aqueous solutions of zinc(II) chloride. Evidence of ion complexes. J. Phys. Chem. 1987, 91, 2206-2211.

(37) Soper, A. K.; Neilson, G. W.; Enderby, J. E.; Howe, R. A. A neutron diffraction study of hydration effects in aqueous solutions. J. Phys. C 1977, 10, 1793.

(38) Neilson, G. W.; Enderby, J. E. The hydration of $\mathrm{Ni}^{2+}$ in aqueous solutions. J. Phys. C 1978, 11, L625.

(39) Sandstrom, D. R. Determination of structural parameters from EXAFS: Application to solutions and catalysts. Nuovo Cimento D 1984, 3, 825-845.

(40) Caminiti, R.; Licheri, G.; Paschina, G.; Piccaluga, G.; Pinna, G. X-ray diffraction and structural properties of aqueous solutions of divalent metal-chlorides. Z. Naturforsch. A 1980, 35, 1361-1367.

(41) Maeda, M.; Ito, T.; Hori, M.; Johansson, G. The structure of zinc chloride complexes in aqueous solution. Z. Naturforsch. A 1996, 51, 63-70.

(42) Harris, D. J.; Brodholt, J. P.; Sherman, D. M. Zinc Complexation in Hydrothermal Chloride Brines: Results from ab Initio Molecular Dynamics Calculations. J. Phys. Chem. A 2003, 107, 1050-1054. 
(43) Delwaulle, M. Etude au moyen de l'effet Raman de la constitution des solutions d'iodure, de bromure et de chlorure de zinc dissous seuls ou en présence d'ions halogènes - Mise en évidence des molécules non ionisées $\mathrm{ZnX}_{2}$ et des ions $\mathrm{ZnX}_{4}^{--}$. C. R. Acad. Sci. (France) 1955, 240, 2132-2134.

(44) Quicksall, C.; Spiro, T. Raman spectra of terachlorozincates and the structure of $\mathrm{ZnCl}_{4}^{2-}$. Inorg. Chem. 1966, 5, 2232-2233.

(45) Magini, M. Hydration and complex formation study on concentrated $\mathrm{MCl} 2$ solutions $[\mathrm{M}=\mathrm{Co}(\mathrm{II}), \mathrm{Ni}(\mathrm{II}), \mathrm{Cu}(\mathrm{II})]$ by x-ray diffraction technique. J. Chem. Phys. 1981, 74, $2523-2529$.

(46) Beagley, B.; McAuliffe, C.; Smith, S.; White, E. EXAFS studies of aqueous solutions of manganese (II) chloride and bromide: structural variations with concentration and interactions with solvent. J. Phys. Condens. Matter 1991, 3, 7919.

(47) Musinu, A.; Paschina, G.; Piccaluga, G.; Magini, M. X-ray diffraction study of $\mathrm{CoCl}_{2}-$ LiCl aqueous solutions. J. Chem. Phys. 1984, 80, 2772-2776.

(48) D’Angelo, P.; Bottari, E.; Festa, M. R.; Nolting, H.-F.; Pavel, N. V. Structural investigation of copper(II) chloride solutions using x-ray absorption spectroscopy. J. Chem. Phys. 1997, 107, 2807-2812.

(49) Dreier, P.; Rabe, P. EXAFS-study of the $\mathrm{Zn}^{2+}$ coordination in aqueous halide solutions. J. Phys. Colloq. 1986, 47, C8-809.

(50) Goldberg, R.; Manley, J.; Nuttal, R. Program Gamphi for Calculating Activity and Osmotic Coefficients of Aqueous Electrolyte Solutions at 298.15 K. 1984.

(51) Blum, L. In Theoretical Chemistry, Advances and Perspectives; Eyring, H., Henderson, D., Eds.; Academic Press: New York, 1980; Vol. 5.

(52) Friedman, H. L. A course in statistical mechanics; Prentice-Hall, 1985. 
(53) Stigter, D. Interactions in aqueous solutions. II. Osmotic pressure and osmotic coefficient of sucrose and glucose solutions. J. Phys. Chem. 1960, 64, 118-124.

(54) Simonin, J.-P.; Blum, L.; Turq, P. Real Ionic Solutions in the Mean Spherical Approximation. 1. Simple Salts in the Primitive Model. J. Phys. Chem. 1996, 100, 7704-7709.

(55) Simonin, J.-P. Study of experimental-to-McMillan-Mayer conversion of thermodynamic excess functions. J. Chem. Soc. Faraday Trans. 1996, 92, 3519-3523.

(56) Jenkins, H.; Thakur, K. Reappraisal of thermochemical radii for complex ions. J. Chem. Educ. 1979, 56, 576 .

(57) Huheey, J. E.; Keiter, E. A.; Keiter, R. L.; Medhi, O. K. Inorganic chemistry: principles of structure and reactivity; Pearson Education India, 2006.

(58) Schatzberg, P. Molecular diameter of water from solubility and diffusion measurements. J. Phys. Chem. 1967, 71, 4569-4570.

(59) Ben-Naim, A. In The Physics and Physical Chemistry of Water; Franks, F., Ed.; Springer New York: Boston, MA, 1972; pp 413-442.

(60) Jones, M. M.; Jones, E. A.; Harmon, D. F.; Semmes, R. T. A search for perchlorate complexes. Raman spectra of perchlorate solutions. J. Am. Chem. Soc. 1961, 83, 20382042.

(61) Ohtaki, H.; Johansson, G. X-ray diffraction studies on the structures of cadmium iodide complexes in water and in DMSO solutions. Pure Applied Chem. 1981, 53, 1357-1364.

(62) Smithson, J.; Williams, R. A possible differentiation between ion-pairs and complexes. J. Chem. Soc. 1958, 457-462.

(63) Bockris, J. O.; Reddy, A. K. Modern Electrochemistry; Kluwer, 2002; Vol. 1. 
(64) Moore, G. E.; Kraus, K. A. Anion exchange studies. IV. Cobalt and nickel in hydrochloric acid solutions. J. Am. Chem. Soc. 1952, 74, 843-844.

(65) Herber, R. H.; Irvine Jr, J. W. Anion-exchange Studies. III. Ni(II) in Aqueous Hydrochloric Acid and Lithium Chloride. J. Am. Chem. Soc. 1956, 78, 905-907.

(66) Downes, C. J. Osmotic and activity coefficients for system $\mathrm{NaCl}-\mathrm{MnCl}_{2}-\mathrm{H}_{2} \mathrm{O}$ at $25^{\circ} \mathrm{C}$. J. Chem. Eng. Data 1973, 18, 412-416.

(67) Downes, C. Thermodynamics of mixed electrolyte solutions: The systems $\mathrm{H}_{2} \mathrm{O}-\mathrm{NaCl}-$ $\mathrm{CoCl}_{2}$ and $\mathrm{H}-2 \mathrm{O}-\mathrm{CaCl}_{2}-\mathrm{CoCl}_{2}$ at $25^{\circ} \mathrm{C}$. J. Solution Chem. 1975, 4, 191-204.

(68) Filippov, V.; Rumyantsev, A.; Charykov, N. Thermodynamic study of the ternary system $\mathrm{K}^{+}, \mathrm{Co}^{2+} \| \mathrm{Cl}^{-}-\mathrm{H}_{2} \mathrm{O}$ AND K ${ }^{+}, \mathrm{Ni}^{2+} \| \mathrm{Cl}^{-}-\mathrm{H}_{2} \mathrm{O}$ at $25^{\circ} \mathrm{C}$. J. Applied Chem. USSR 1991,64 .

(69) Downes, C. J.; Pitzer, K. S. Thermodynamics of electrolytes. Binary mixtures formed from aqueous $\mathrm{NaCl}, \mathrm{Na}_{2} \mathrm{SO}_{4}, \mathrm{CuCl}_{2}$, and $\mathrm{CuSO}_{4}$, at $25^{\circ} \mathrm{C}$. J. Solution Chem. 1976, 5, $389-398$.

(70) Tialowska-Mocharla, H.; Manohar, S.; Atkinson, G. Activity coefficient measurements of the system $\mathrm{HCl}-\mathrm{ZnCl}_{2}-\mathrm{H}_{2} \mathrm{O}$ at 25 and $35^{\circ} \mathrm{C}$. J. Solution Chem. 1992, 21, 545-555.

(71) Pan, C. F.; Argersinger Jr, W. J. Isopiestic determination of the osmotic and relative activity coefficients in $\mathrm{BaCl}_{2}-\mathrm{ZnCl}_{2}-\mathrm{H}_{2} \mathrm{O}$ at $25^{\circ} \mathrm{C}$. J. Chem. Eng. Data 1987, 32, 205210.

(72) Reilly, P.; Stokes, R. The activity coefficients of cadmium chloride in water and sodium chloride solution at $25^{\circ}$. Aust. J. Chem. 1970, 23, 1397-1406.

(73) Marcus, Y.; Maydan, D. Anion exchange of metal complexes. VIII. The effect of the secondary cation. The zinc-chloride system. J. Phys. Chem. 1963, 67, 979-983. 
(74) Luo, Y.; Millero, F. J. Stability constants for the formation of lead chloride complexes as a function of temperature and ionic strength. Geochim. Cosmochim. Acta 2007, 71, $326-334$.

(75) Hefter, G. Stability constants for the lead (II)-halide systems. Polyhedron 1990, 9, 2429-2432.

(76) Triolo, R.; Blum, L.; Floriano, M. Simple electrolytes in the mean spherical approximation. 2. Study of a refined model. The Journal of Physical Chemistry 1978, 82, $1368-1370$.

\section{Abstract Graphic}

\section{Self-complexing electrolyte mixture}

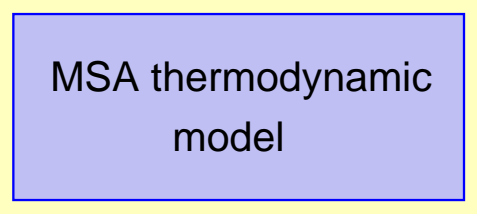

Experimental data:

- osmotic coefficient

- (speciation)

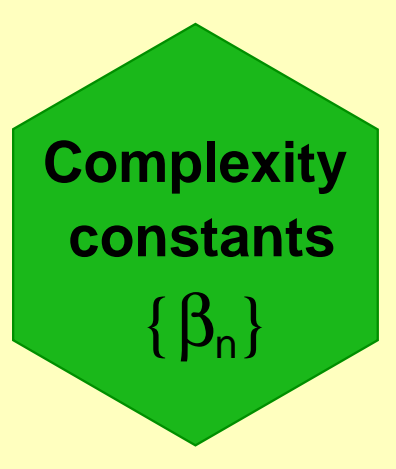




\title{
Supporting Information
}

\section{Determination of thermodynamic complexity}

constants and speciation for multi-complexing

electrolytes within the mean spherical

approximation model

\author{
Jean-Pierre Simonin* \\ CNRS, Laboratoire PHENIX, Campus P.M. Curie, Sorbonne Universités, F-75005, Paris, \\ France.
}

E-mail: jpsimonin@gmail.com 


\section{Calculation of concentrations and partial molar volumes}

Concentrations and partial molar volumes of salts were derived from an expression for the density of solution. In ref. I, the density of binary solutions of a salt S was represented by the formula,

$$
d=d_{0}+d_{1 S} m_{S}-d_{2 S} m_{S}^{3 / 2}
$$

in which $d_{0}$ is the density of pure water, $m_{S}$ the molality of salt $S$, and $d_{1 S}$ and $\mathrm{d}_{2 S}$ are two salt-dependent parameters.

In the present work, it was assumed to have the form,

$$
d=d_{0}+d_{1 A} m_{A}+d_{1 B} m_{B}-\left[d_{2 A}^{2 / 3} m_{A}+d_{2 B}^{2 / 3} m_{B}\right]^{3 / 2}
$$

The form of Eq. S2 was inspired from an equation in terms of concentrations. ${ }^{1}$

The concentration, $C_{i}$, of any species $i$ can be found from its molality $m_{i}$ as,

$$
C_{i}=m_{i} / V
$$

in which $V$ is the specific volume of solution, i.e. the volume of solution per $\mathrm{kg}$ of water in the solution. One has,

$$
V=\frac{1+m_{A} M_{A}+m_{B} M_{B}}{d}
$$

with $M_{S}$ the molar mass of salt $\mathrm{S}$ (in $\mathrm{kg}$ ) and $d$ the density given by Eq. S2.

The partial molar volume of salt $\mathrm{S}\left(=\mathrm{A}\right.$ or B) in a mixture, $V_{S}=\partial V / \partial m_{S}$, can be obtained by analytic differentiation of Eq. S4 with $d$ given by Eq. S2. The software Maple was used to handle this type of symbolic calculation throughout, and to translate the formulas directly into FORTRAN. 


\section{Results for solution densities}

Experimental densities of binary solutions at $25^{\circ} \mathrm{C}$ were fitted using Eq. S1. The results for the parameters $d_{1 S}$ and $d_{2 S}$ are given in Table S1.

Table S1: Values of parameters for the computation of densities (Eqs. S1 and S2).

\begin{tabular}{|c|c|c|c|c|c|}
\hline Salt & $\begin{array}{c}\text { Max. m } \\
\left(\mathrm{mol} \mathrm{kg}^{-1}\right)\end{array}$ & $\begin{array}{c}10^{2} d_{1 S} \\
\left(\mathrm{~kg}^{2} /(\mathrm{mol} \mathrm{L})\right)\end{array}$ & $\begin{array}{c}10^{2} d_{2 S} \\
\left(\mathrm{~kg}^{5 / 2} /\left(\mathrm{mol}^{3 / 2} \mathrm{~L}\right)\right)\end{array}$ & Accuracy of fit & Ref. $^{a}$ \\
\hline $\mathrm{HCl}$ & 4 & 1.89148 & 0.170817 & $6 \times 10^{-3} \%$ & 2 \\
\hline $\mathrm{LiCl}$ & 4 & 2.53093 & 0.227843 & $0.03 \%$ & 2 \\
\hline $\mathrm{NaCl}$ & 4 & 4.23057 & 0.381813 & $0.1 \%$ & 2 \\
\hline $\mathrm{KCl}$ & 4.5 & 5.04061 & 0.581023 & $0.02 \%$ & 2 \\
\hline $\mathrm{MgCl}_{2}$ & 5 & 8.41791 & 1.10935 & $0.05 \%$ & 3 \\
\hline $\mathrm{CaCl}_{2}$ & 6 & 10.1650 & 1.49852 & $0.1 \%$ & 3 \\
\hline $\mathrm{SrCl}_{2}$ & 2.5 & 16.0017 & 2.85646 & $0.1 \%$ & 3 \\
\hline $\mathrm{BaCl}_{2}$ & 1.5 & 19.0703 & 1.93576 & $0.03 \%$ & 3 \\
\hline $\mathrm{MnCl}_{2}$ & 3.4 & 11.1048 & 1.14697 & $0.02 \%$ & 4 \\
\hline $\mathrm{CoCl}_{2}$ & 3.4 & 12.3901 & 1.20679 & $0.03 \%$ & 4 \\
\hline $\mathrm{NiCl}_{2}$ & 4.2 & 12.7684 & 1.26227 & $0.03 \%$ & 5 \\
\hline $\mathrm{CuCl}_{2}$ & 3.4 & 12.7772 & 1.35953 & $0.1 \%$ & 6 \\
\hline $\mathrm{ZnCl}_{2}$ & 6 & 12.7067 & 1.92410 & $0.11 \%$ & 7,8 \\
\hline $\mathrm{CdCl}_{2}$ & 2.9 & 16.6494 & 1.70186 & $0.02 \%$ & 7,8 \\
\hline $\mathrm{Mn}\left(\mathrm{ClO}_{4}\right)_{2}$ & 2.8 & 19.7566 & 3.26985 & $0.07 \%$ & 4 \\
\hline $\mathrm{Co}\left(\mathrm{ClO}_{4}\right)_{2}$ & 1.9 & 20.6958 & 3.00392 & $0.05 \%$ & 4 \\
\hline $\mathrm{Ni}\left(\mathrm{ClO}_{4}\right)_{2}$ & 1.0 & 20.5694 & 2.42455 & $0.02 \%$ & 9 \\
\hline $\mathrm{Cu}\left(\mathrm{ClO}_{4}\right)_{2}$ & 5.1 & 22.0968 & 3.77644 & $0.1 \%$ & 10 \\
\hline $\mathrm{Pb}\left(\mathrm{ClO}_{4}\right)_{2}{ }^{b}$ & 12.6 & 32.7213 & 4.95328 & - & 11 \\
\hline
\end{tabular}

${ }^{a}$ References for experimental data; ${ }^{b} d_{1 S}$ and $d_{2 S}$ values assessed using the density value of ref. 10 at saturation, Eq. 31 of ref. ${ }^{12}$ and infinite dilution partial molar volume data for $\mathrm{Pb}^{2+}$ and $\mathrm{ClO}_{4}^{-}$ions. ${ }^{13,14}$

Then, the accuracy of Eq. S2 to describe the densities of ternary solutions of chloride salts at $25^{\circ} \mathrm{C}$ was examined in the case of strong and associating electrolyte mixtures. Such systems are not plentiful but data for three mixtures were found in the literature. In this comparison with experimental values no new parameter was introduced. The results are shown in Table S2.

These results may suggest that Eq. S2 gives accurate results for the estimation of ternary solution densities of strong electrolytes up to high concentrations, and probably less accurate 
Table S2: Results for the densities of ternary aqueous electrolyte mixtures (using Eq. S2).

\begin{tabular}{lccl}
\hline Mixture & $\begin{array}{c}\text { Max. I } \\
(\text { mol L }\end{array}$ & Accuracy of fit & Ref. \\
\hline $\mathrm{CaCl}_{2}+\mathrm{NaCl}$ & 11.2 & $0.05 \%$ & 15 \\
$\mathrm{CaCl}_{2}+\mathrm{KCl}$ & 6.5 & $0.06 \%$ & 15 \\
$\mathrm{ZnCl}_{2}+\mathrm{KCl}$ & 9.8 & $0.7 \%$ & 16 \\
\hline
\end{tabular}

${ }^{a}$ Maximum ionic strength: $I=\frac{1}{2} \sum Z_{i}^{2} C_{i}$, summed on all ions (on a complete dissociation basis).

results in the case of a self-associating salt mixed with a strong salt. Nevertheless, this latter accuracy should be sufficient in this work in which densities are used to compute concentrations.

\section{Results for the proportion of free cation, $p_{0}$, and for $N_{C l}$}

Table S3: Experimental (exp) and calculated (cal) values for $p_{0}$ and $p_{1}$, and the mean coordination number, $N_{C l}$, for the $\beta_{n}$ values of Table 6 .

\begin{tabular}{lccccc}
\hline Salt & Concentration & $p_{0}^{\text {exp }}$ & $p_{0}^{\text {cal }}$ & $N_{C l}^{\text {exp }}$ & $N_{C l}^{\text {cal }}$ \\
\hline $\mathrm{MnCl}_{2}$ & $1 \mathrm{M}$ & & & 0.4 & 0.6 \\
$\mathrm{CuCl}_{2}$ & $0.1 \mathrm{M} \mathrm{CuCl}_{2}+0.8 \mathrm{M} \mathrm{NaCl}$ & & & 0.8 & 0.41 \\
& $0.1 \mathrm{M} \mathrm{CuCl}_{2}+2.8 \mathrm{M} \mathrm{NaCl}$ & & & 1 & 1.2 \\
$\mathrm{ZnCl}_{2}$ & $1.62 \mathrm{M}$ & 0.51 & 0.45 & & \\
& $2.08 \mathrm{M}$ & 0.46 & 0.40 & & \\
& $1 \mathrm{~mol} \mathrm{~kg}^{-1}$ & & & 0.9 & 0.88 \\
& $2 \mathrm{~mol} \mathrm{~kg}^{-1}$ & & & 1.6 & 1.42 \\
\hline
\end{tabular}

\section{References}

(1) Söhnel, O.; Novotnỳ, P. Densities of aqueous solutions of inorganic substances; Elsevier Publishing Company, 1985; Vol. 22.

(2) Ruby, C. E.; Kawai, J. The densities, equivalent conductances and relative viscosities at $25^{\circ}$, of solutions of hydrochloric acid, potassium chloride and sodium chloride, and 
of their binary and ternary mixtures of constant chloride-ion-constituent content. $J$. Am. Chem. Soc. 1926, 48, 1119-1128.

(3) Isono, T. Density, viscosity, and electrolytic conductivity of concentrated aqueous electrolyte solutions at several temperatures. Alkaline-earth chlorides, $\mathrm{LaCl}_{3}, \mathrm{Na}_{2} \mathrm{SO}_{4}$, $\mathrm{NaNO}_{3}, \mathrm{NaBr}, \mathrm{KNO}_{3}, \mathrm{KBr}$, and $\mathrm{Cd}\left(\mathrm{NO}_{3}\right)_{2}$. J. Chem. Eng. Data 1984, 29, 45-52.

(4) Pogue, R. F.; Atkinson, G. Solution thermodynamics of first-row transition elements. 2. Apparent molal volumes of aqueous $\mathrm{MnCl}_{2}, \mathrm{Mn}\left(\mathrm{ClO}_{4}\right)_{2}, \mathrm{CoCl}_{2}, \mathrm{Co}\left(\mathrm{ClO}_{4}\right)_{2}, \mathrm{FeCl}_{2}$, and $\mathrm{Fe}\left(\mathrm{ClO}_{4}\right)_{2}$, from 15 to $55^{\circ} \mathrm{C}$. J. Chem. Eng. Data 1989, 34, 227-232.

(5) Stokes, R. H.; Phang, S.; Mills, R. Density, conductance, transference numbers, and diffusion measurements in concentrated solutions of nickel chloride at 25 C. J. Solution Chem. 1979, 8, 489-500.

(6) Berthier, P.; Courty, C.; Gauthier, J. Sur le paramagnétisme du chlorure cuivrique en solution aqueuse. C. R. Hebd. Seances Acad. Sci. 1952, 234, 604-606.

(7) D'Ans, J.; Surawski, H.; Synowietz, C. Densities of binary aqueous systems and heat capacities of liquid systems. Landolt-Börnstein database: Numerical Data and Functional Relationships in Science and Technology. Group IV: Macroscopic and Technical Properties of Matter; Springer Berlin, Heidelberg, New York, 1977; Vol. 1.

(8) Timmermans, J. The Physico-chemical Constants of Binary Systems in Concentrated Solutions: Systems with metallic compounds; Interscience publishers, 1960; Vol. 3.

(9) Pogue, R.; Atkinson, G. Solution thermodynamics of first-row transition elements. 1. Apparent molal volumes of aqueous $\mathrm{NiCl}_{2}, \mathrm{Ni}\left(\mathrm{ClO}_{4}\right)_{2}, \mathrm{CuCl}_{2}$, and $\mathrm{Cu}\left(\mathrm{ClO}_{4}\right)_{2}$, from 15 to $55^{\circ}$ C. J. Chem. Eng. Data 1988, 33, 370-376.

(10) Berthier, P.; Courty, C.; Gauthier, J. Sur les propriétés magnétiques des solutions aqueuses de perchlorate cuivrique. C. R. Hebd. Seances Acad. Sci. 1954, 239, 241-243. 
(11) Willard, H.; Kassner, J. Preparation and properties of lead perchlorate. J. Am. Chem. Soc. 1930, 52, 2391-2396.

(12) Simonin, J.-P.; Bernard, O. Organic electrolyte solutions: Modeling of deviations from ideality within the binding mean spherical approximation. Fluid Phase Equilib. 2018, $468,58-69$.

(13) Millero, F. J. Molal volumes of electrolytes. Chem. Rev. 1971, 71, 147-176.

(14) Marcus, Y. The standard partial molar volumes of ions in solution. Part 4. Ionic volumes in water at $0-100^{\circ}$ C. J. Phys. Chem. B 2009, 113, 10285-10291.

(15) Zhang, H.-L.; Chen, G.-H.; Han, S.-J. Viscosity and density of $\mathrm{H}_{2} \mathrm{O}+\mathrm{NaCl}+\mathrm{CaCl}_{2}$ and $\mathrm{H}_{2} \mathrm{O}+\mathrm{KCl}+\mathrm{CaCl}_{2}$ at 298.15 K. J. Chem. Eng. Data 1997, 42, 526-530.

(16) Rard, J. A.; Miller, D. G. Ternary mutual diffusion coefficients of ZnCl 2- KCl- H 2 O at 25 C by Rayleigh interferometry. J. Solution Chem. 1990, 19, 129-148. 